\title{
Is vitamin D-fortified yogurt a value-added strategy for improving human health? A systematic review and meta-analysis of randomized trials
}

\author{
C. Gasparri, ${ }^{1 *}$ S. Perna, ${ }^{2}$ D. Spadaccini, ${ }^{1}$ T. Alalwan, ${ }^{2}$ C. Girometta, ${ }^{3}$ V. Infantino, ${ }^{4}$ and M. Rondanelli ${ }^{5,6}$ \\ ${ }^{1}$ Department of Public Health, Experimental and Forensic Medicine, Section of Human Nutrition, Endocrinology and Nutrition Unit, \\ Azienda di Servizi alla Persona, University of Pavia, 27100 Pavia, Italy \\ ${ }^{2}$ Department of Biology, College of Science, University of Bahrain, Sakhir Campus, PO Box 32038, Kingdom of Bahrain \\ ${ }^{3}$ Department of Earth and Environmental Sciences, Mycology and Plant Pathology Laboratory, University of Pavia, 27100 Pavia, Italy \\ ${ }^{4}$ Department of Biomedical Sciences and Human Oncology, University of Bari Aldo Moro, 70121 Bari, Italy \\ ${ }^{5}$ IRCCS Mondino Foundation, 27100 Pavia, Italy \\ ${ }^{6}$ Department of Public Health, Experimental and Forensic Medicine, Unit of Human and Clinical Nutrition, University of Pavia, 27100 Pavia, Italy
}

\section{ABSTRACT}

Yogurt is a good source of probiotics, calcium, and proteins, but its content of vitamin $\mathrm{D}$ is low. Therefore, yogurt could be a good choice for vitamin D fortification to improve the positive health outcomes associated with its consumption. The primary aim of this systematic review and meta-analysis was to investigate the effect of vitamin D-fortified yogurt compared with plain yogurt on levels of serum 25-hydroxy vitamin $\mathrm{D}$ (25OHD). The secondary aim was to evaluate the effect of fortified yogurt on parathyroid hormone, anthropometric parameters, blood pressure, glucose metabolism, and lipid profile. We searched PubMed, Scopus, and Google Scholar for eligible studies; that is, randomized controlled trials (RCT) that compared vitamin D-fortified yogurt with control treatment without any additional supplement. Random-effects models were used to estimate pooled effect sizes and $95 \%$ confidence intervals. Findings from $9 \mathrm{RCT}(\mathrm{n}=665$ participants $)$ that lasted from 8 to $16 \mathrm{wk}$ are summarized in this review. The meta-analyzed mean differences for random effects showed that vitamin D-fortified yogurt (from 400 to 2,000 IU) increased serum 25OHD by $31.00 \mathrm{nmol} / \mathrm{L}$. In addition, vitamin D-fortified yogurt decreased parathyroid hormone by $15.47 \mathrm{ng} / \mathrm{L}$, body weight by $0.92 \mathrm{~kg}$, waist circumference by $2.01 \mathrm{~cm}$, HOMA-IR by 2.18 mass units, fasting serum glucose by $22.54 \mathrm{mg} / \mathrm{dL}$, total cholesterol by $13.38 \mathrm{mg} / \mathrm{dL}$, and triglycerides by $30.12 \mathrm{mg} / \mathrm{dL}$ compared with the controlled treatments. No publication bias was identified. Considerable between-study heterogeneity was observed for most outcomes. Vitamin D-fortified yogurt may be beneficial in improving serum 25OHD, lipid profile, glucose metabolism, and anthropometric parameters

Received November 26, 2018.

Accepted June 6, 2019.

*Corresponding author: clara.gasparri01@universitadipavia.it and decreasing parathyroid hormone level in pregnant women and adult and elderly subjects with or without diabetes, prediabetes, or metabolic syndrome.

Key words: fortified yogurt, vitamin D, health, waist circumference, parathyroid hormone

\section{INTRODUCTION}

Yogurt is a particular type of fermented milk and, although its nutritional content is comparable to that of milk, added ingredients and fermentation may improve its nutritional value (Adolfsson et al., 2004) and provide unique properties that enhances the bioavailability of its nutrients (Wang et al., 2013; El-Abbadi et al., 2014). A wide variety of different fermented milk products are available, including probiotic, prebiotic, and functional fermented milks. The term "yogurt" refers to the product obtained from the fermentation of milk by 2 viable lactic acid bacteria, Lactobacillus bulgaricus and Streptococcus thermophilus, at a minimum concentration of $10^{7} \mathrm{cfu} / \mathrm{g}$ at the time of manufacture (WHO/FAO, 2011).

Probiotics have beneficial effects on antibiotic-associated diarrhea (Goldenberg et al., 2017), inflammatory bowel diseases (Ghouri et al., 2014), depression and anxiety (Luna and Foster, 2015), and immune function (Ozen et al., 2015). In addition, recent evidence shows promising results with probiotic therapy in the management of obesity (Zhang et al., 2015) and in the reduction of low-density lipoprotein cholesterol (DiRienzo, 2014) and high blood pressure (Khalesi et al., 2014).

Yogurt provides an excellent source of essential amino acids. The proteolytic activity of bacterial cultures in yogurt enables some predigestion of milk proteins, resulting in greater amounts of free amino acids that allow for better protein digestibility (Adolfsson et al., 2004). Although yogurt contains lactose, it is well tolerated by individuals with lactose intolerance. Auto-digestion of lactose by yogurt bacteria improves 
its absorption, compared with other dairy products, in lactase-deficient people (Savaiano, 2014). Moreover, the activity of bacteria in yogurt results in an acidic environment that increases the bioavailability of calcium, potassium, phosphorus, and zinc compared with milk (Adolfsson et al., 2004).

Thus, yogurt provides both calcium and proteins, but the usual content of vitamin $\mathrm{D}$ is low, ranging between 2 and $3 \mu \mathrm{g}$ (USDA, 2014), which is below the recommended dietary allowance of $15 \mu \mathrm{g} / \mathrm{d}$ (600 IU) up to the age of $70 \mathrm{yr}$ (Ross et al., 2011). Vitamin D, calcium, and proteins together are important to help reduce the negative bone balance often observed in the elderly.

Yogurt may be supplemented with vitamin D and additional probiotics to improve the positive health outcomes (El-Abbadi et al., 2014). For this reason, yogurt could be a good choice for vitamin $\mathrm{D}$ fortification. Jafari et al. (2016a) evaluated the stability of vitamin $\mathrm{D}_{3}$ added to low-fat yogurt and the yogurt drink "doogh" during 3 wk of product shelf life. The authors considered 2 types of vitamin $\mathrm{D}_{3}$, water- and oil-dispersible forms, suitable for food fortification, and 2 types of containers, opaque and translucent. The stability of vitamin $\mathrm{D}_{3}$ in yogurt or doogh packed in translucent containers was not satisfactory, whereas that of yogurt or doogh in opaque containers (which reduce light-related degradation) was acceptable (Jafari et al., 2016a).

Vitamin D deficiency leads to several clinical disorders, including bone metabolic disorders (Naylor and Eastell, 2012), secondary hyperparathyroidism (Lips et al., 2006), and muscle weakness that could result in a higher risk of falls in the elderly (Bischoff-Ferrari et al., 2009). Cardiovascular disease (CVD), cancers, both types of diabetes (Holick et al., 2011), obesity (Pereira-Santos et al., 2015), and higher susceptibility of immune-mediated disorders, including chronic infections and autoimmune disease (Baeke et al., 2010) are commonly known diseases associated with vitamin $\mathrm{D}$ inadequacy. Currently, there is a lack of agreement regarding the serum concentration of 25-hydroxy vitamin D (25OHD) that would be considered a deficiency threshold level. The WHO (2003) defined as normal a serum concentration of $25 \mathrm{OHD}>20 \mathrm{ng} / \mathrm{mL}$, whereas, according to the International Osteoporosis Foundation (IOF), an optimal state of nutrition would occur with $25 \mathrm{OHD}$ levels $>30 \mathrm{ng} / \mathrm{mL}$ (Dawson-Hughes et al., 2010). Therefore, the minimum value to define a completely adequate nutrition status would be $30 \mathrm{ng} /$ $\mathrm{mL}$ (Holick et al., 2011). The reference intake levels for the Italian population indicate a population reference intake of 15 for adults (aged 18-59 yr), which is the same as that in the 60-74 yr age group. For the elderly (>75 yr), a PRI of 20 is adopted (SINU, 2014). Most populations fail to meet the recommended dietary vita- min D requirements. In Europe, 25OHD concentrations $<30 \mathrm{nmol} / \mathrm{L}(12 \mathrm{ng} / \mathrm{mL})$ and $<50 \mathrm{nmol} / \mathrm{L}(20 \mathrm{ng} / \mathrm{mL})$ are present in 13 and $40.4 \%$ of the general population, respectively (Pilz et al., 2018).

Vitamin D fortification seems to be the most appropriate means to improve vitamin D intake and status in the general population to meet dietary vitamin D recommendations. Today, wide variation exists in the availability of vitamin D-fortified foods, and mandatory and voluntary vitamin D food fortification policies may be enforced globally. Systematic vitamin D food fortification has been introduced in some countries, such as the United States, Canada, India, and Finland. For example, in the Finnish population, vitamin D nutrition policy represents a successful public health strategy (Pilz et al., 2018).

Yogurt fortification could be a good strategy to improve some of the most common nutritional deficiencies. As a product, yogurt represents a feasible approach to enhance nutritional status and is well suited for elderly individuals; there are no obstacles in consumption for individuals with chewing difficulty, it is well tolerated by lactose-intolerant individuals, and it has relatively long shelf life (El-Abbadi et al., 2014).

The primary aim of this systematic review and meta-analysis was to investigate the effect of vitamin D-fortified yogurt compared with plain yogurt on serum 25OHD in a cohort of pregnant, adult, and elderly subjects with or without diabetes, prediabetes, or metabolic syndrome. The secondary aim was to evaluate the effect of fortified yogurt on parathyroid hormone (PTH) levels, anthropometric parameters such as BW, waist circumference, and body mass index (BMI), and blood pressure, lipid profile, and glucose metabolism.

\section{MATERIALS AND METHODS}

The present systematic review was conducted in accordance with the Preferred Reporting Items for Systematic Review and Meta-Analyses (PRISMA) statement (Moher et al., 2009). It was carried out through the following steps: (1) formulation of the review question: "What are the health outcomes associated with vitamin D-fortified yogurt consumption?"; (2) definition of participants: women and men aged 18 to 99 yr; (3) search strategy for the identification of relevant intervention studies that included the effect of vitamin D-fortified yogurt; and (4) analysis of the data through the systematic review and meta-analysis.

\section{Search Strategy}

Articles written in English were identified by searching Pubmed (https://www.ncbi.nlm.nih.gov/pubmed/ 
), Scopus (https://www.scopus.com/home.uri), and Google Scholar (https://scholar.google.it/). The search strategy was based on the following search terms: vitamin $\mathrm{D}[\mathrm{MeSH}$ Terms]) OR cholecalciferol[MeSH Terms]) OR vitamin D2[MeSH Terms]) OR 1,25 dihydroxycholecalciferol[MeSH Terms]) OR fortified yogurt vitamin $\mathrm{D}[\mathrm{MeSH}$ Terms]) OR calcitriol[MeSH Terms]) OR vitamin D3[MeSH Terms]) OR ergocalciferols[MeSH Terms]) AND body weight[MeSH Terms]) OR body mass index[MeSH Terms]) OR waist circumference[MeSH Terms]) OR glycemia[MeSH Terms]) OR parathyroid hormone[MeSH Terms]) OR triglycerides[MeSH Terms]) OR cholesterol[MeSH Terms]) OR blood pressure[MeSH Terms]) OR insulin[MeSH Terms]) OR 25OHD[MeSH Terms]) OR HOMA IR[MeSH Terms]) OR Anthropometric[MeSH Terms]) OR metabolic syndrome[MeSH Terms]) OR fat mass[MeSH Terms]) OR glucose[MeSH Terms]) OR diabetes[MeSH Terms]. This search strategy retrieved 33,917 studies; after initial screening based on titles and pertinence, we entered 48 studies in the flowchart process. The same search was done in the Scopus and Google Scholar search engines, and some studies were retrieved from both databases.

Eligible studies were required to report baseline and follow-up values, the mean change, and relative standard deviation from baseline or the mean difference among intervention groups versus control group, or both, concerning serum 25OHD; PTH; anthropometric outcomes such as BW, BMI, waist circumference, and fat mass; systolic and diastolic blood pressure; glucose metabolism such as fasting serum glucose and insulin resistance (HOMA-IR); and lipid profile, including total cholesterol, triglycerides, low-density lipoprotein (LDL) and high-density lipoprotein (HDL) fractions. Studies in children or studies that were not randomized or had no control group were excluded a priori.

\section{Analysis of Data and Presentation of the Outcomes}

Randomized clinical trials (RCT) investigating the effectiveness of vitamin D-fortified yogurt on different health outcomes were included. For each study, the following data were collected: first author, publication year, study setting, study design, eligibility criteria, number of subjects, sex, age, dietary intervention description, duration, and main outcomes. A metaanalysis of pooled estimates for aggregated data was performed.

\section{Risk of Bias in Individual Studies}

The risk of bias of each study was assessed using the Cochrane Collaboration risk of bias tool (Higgins et al.,
2011) and considering as factors contributing to the study quality the generation of the allocation sequence, the allocation concealment, the blinding of outcome data, the presence of incomplete data, and selective reporting. These factors were classified as low, high, or unclear risk of bias. Studies with a low risk of bias for at least 3 items were considered good; studies with a low risk of bias for at least 2 items were considered fair, and studies with a low risk for no items or only for 1 item were considered poor.

\section{RESULTS}

The literature search, after the initial screening, retrieved 48 eligible articles. After an accurate screening, 19 papers were selected for full-text review. Of these 19 articles, 10 studies were excluded for methodological reasons and $9 \mathrm{RCT}$ were selected for the present systematic review and meta-analysis. Eight studies presented 1 intervention group and 1 control group, and one study used 2 intervention groups and 1 control group (Nikooyeh et al., 2011). Figure 1 shows the study selection procedure.

Concerning the study design, 8 were double-blind RCT (Nikooyeh et al., 2011; Shab-Bidar et al., 2011; Bonjour et al., 2013, 2015; Jafari et al., 2016b; Li and Xing, 2016; Mohammadi-Sartang et al., 2018; Mostafai et al., 2018) and 1 was single-blind RCT (Shab-Bidar et al., 2015a). The studies lasted from 8 to $16 \mathrm{wk}$ and the age range of the subjects was 20 to $99 \mathrm{yr}$. The 9 studies included a total of 665 participants, both women and men (Table 1). Five studies considered a cohort of men and women (397 participants; Nikooyeh et al., 2011; Shab-Bidar et al., 2011, 2015a; Mohammadi-Sartang et al., 2018; Mostafai et al., 2018) and 4 studies considered a cohort of only women (268 participants; Bonjour et al., 2013, 2015; Jafari et al., 2016b; Li and Xing, 2016).

In the eligible studies, 3 involved subjects with type 2 diabetes $(\mathrm{n}=250$; Nikooyeh et al., 2011; Shab-Bidar et al., 2011, 2015a), one study involved prediabetic subjects ( $\mathrm{n}=60$; Mostafai et al., 2018), and 2 studies involved elderly institutionalized women $(\mathrm{n}=100$; Bonjour et al., 2013, 2015). The remaining 3 studies considered pregnant women with gestational diabetes mellitus at the onset of their second trimester $(\mathrm{n}=103$; $\mathrm{Li}$ and Xing, 2016), type 2 diabetic postmenopausal women ( $\mathrm{n}=59$; Jafari et al., 2016b), and subjects with metabolic syndrome $(\mathrm{n}=87$; Mohammadi-Sartang et al., 2018).

The inclusion criteria considered in the selected studies were very different with a wide variety of parameters: low vitamin D status $[\leq 20 \mathrm{nmol} / \mathrm{L}$ or $\leq 30 \mathrm{ng} / \mathrm{mL}(\leq 50$ $\mathrm{nmol} / \mathrm{L}$ )] or baseline serum $25 \mathrm{OHD}<125 \mathrm{nmol} / \mathrm{L}$; serum PTH $<150 \mathrm{ng} / \mathrm{L}$; blood glucose concentration $>126$ 

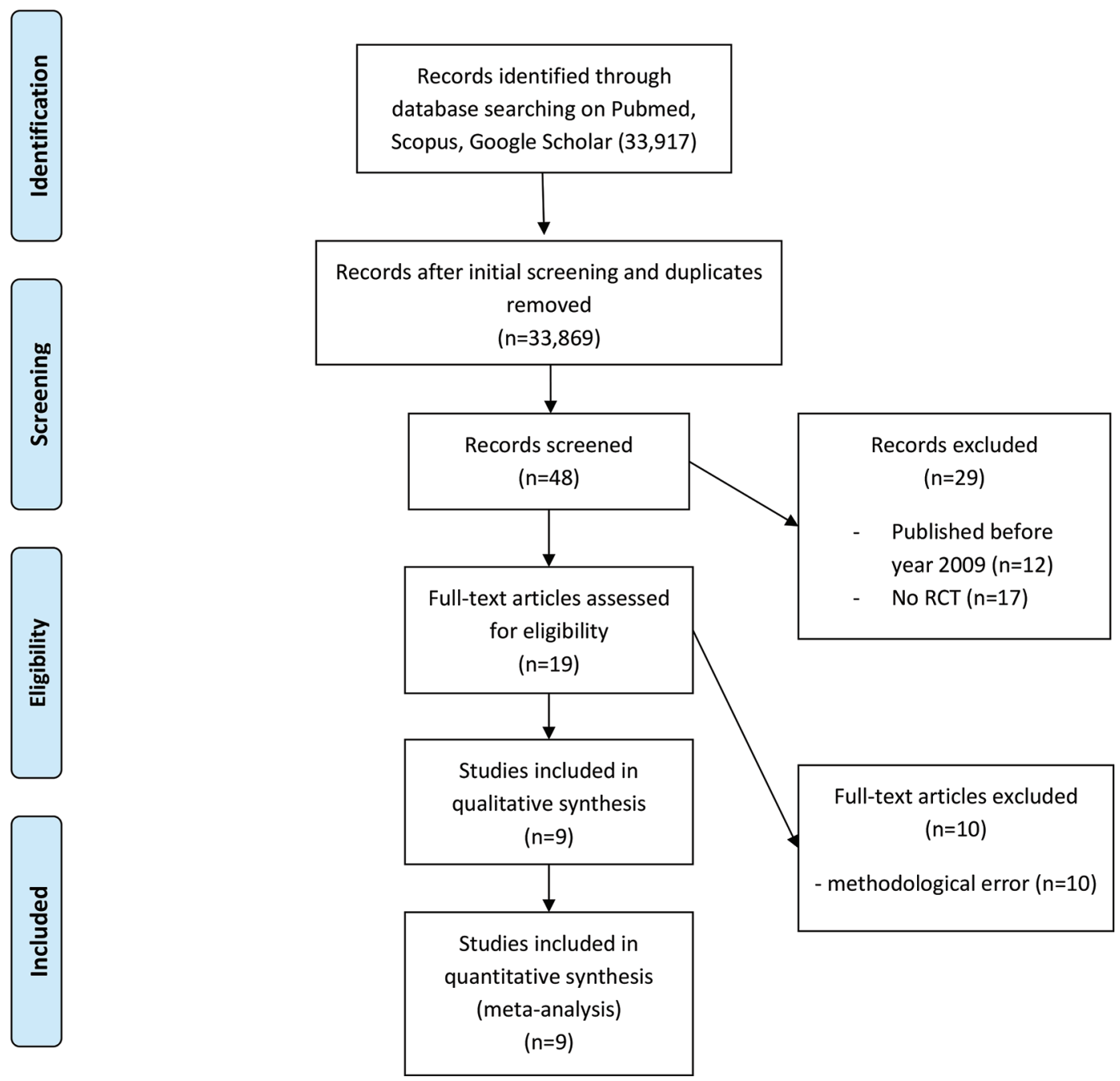

Figure 1. Flow diagram of the study. RCT $=$ randomized controlled trial.

$\mathrm{mg} / \mathrm{dL}$ or $>7 \mathrm{mmol} / \mathrm{L}(>126 \mathrm{mg} / \mathrm{dL})$, BMI between 25 and $35 \mathrm{~kg} / \mathrm{m}^{2}$, prediabetic and type 2 diabetic subjects; pregnant woman whose plasma glucose met one of the following criteria were considered as having gestational diabetes mellitus: fasting plasma glucose $\geq 92 \mathrm{mg} / \mathrm{dL}$, 1-h oral glucose tolerance test $($ OGTT) $\geq 180 \mathrm{mg} / \mathrm{dL}$ : and 2 -h OGTT $\geq 153 \mathrm{mg} / \mathrm{dL}$. Participants in both the intervention and control groups consumed 1 or 2 daily servings (100 $\mathrm{mL}$ for each serving) or 2 daily servings (125-250 mL for each serving) of control yogurt or fortified yogurt. The control group consumed plain yogurt without supplements or plain yogurt with calcium supplement only (doses of 150,170, 280, or $300 \mathrm{mg}$ ). The intervention group consumed vitamin $\mathrm{D}$-fortified yogurt alone (dose of $500,1,000$, or $2,000 \mathrm{IU}$ ) or with vitamin D (dose of 400 or $500 \mathrm{IU}$ ) plus calcium (dose of $150,170,250,500$, or $800 \mathrm{mg})$.

\section{Considering Different Hematochemical Outcomes}

Changes in Serum 25OHD. Seven clinical trials reported a significantly greater increase in circulating 25OHD levels in the intervention groups compared with the control groups (Nikooyeh et al., 2011; Shab-Bidar et al., 2011, 2015a; Bonjour et al., 2013, 2015; Li and Xing, 2016; Mohammadi-Sartang et al., 2018). The range of increase was 15.80 to $40.20 \mathrm{nmol} / \mathrm{L}(P<0.05)$ in subjects who consumed fortified yogurt compared with those who did not. In the other 2 studies, the $P$ values were not reported (Jafari et al., 2016b; Mostafai et al., 2018).

Changes in PTH. Three clinical trials demonstrated significantly lower levels of PTH in the intervention group (Shab-Bidar et al., 2011; Bonjour et al., 2013; Jafari et al., 2016b). The decrease in PTH level varied 
VITAMIN D-FORTIFIED YOGURT AND HUMAN HEALTH

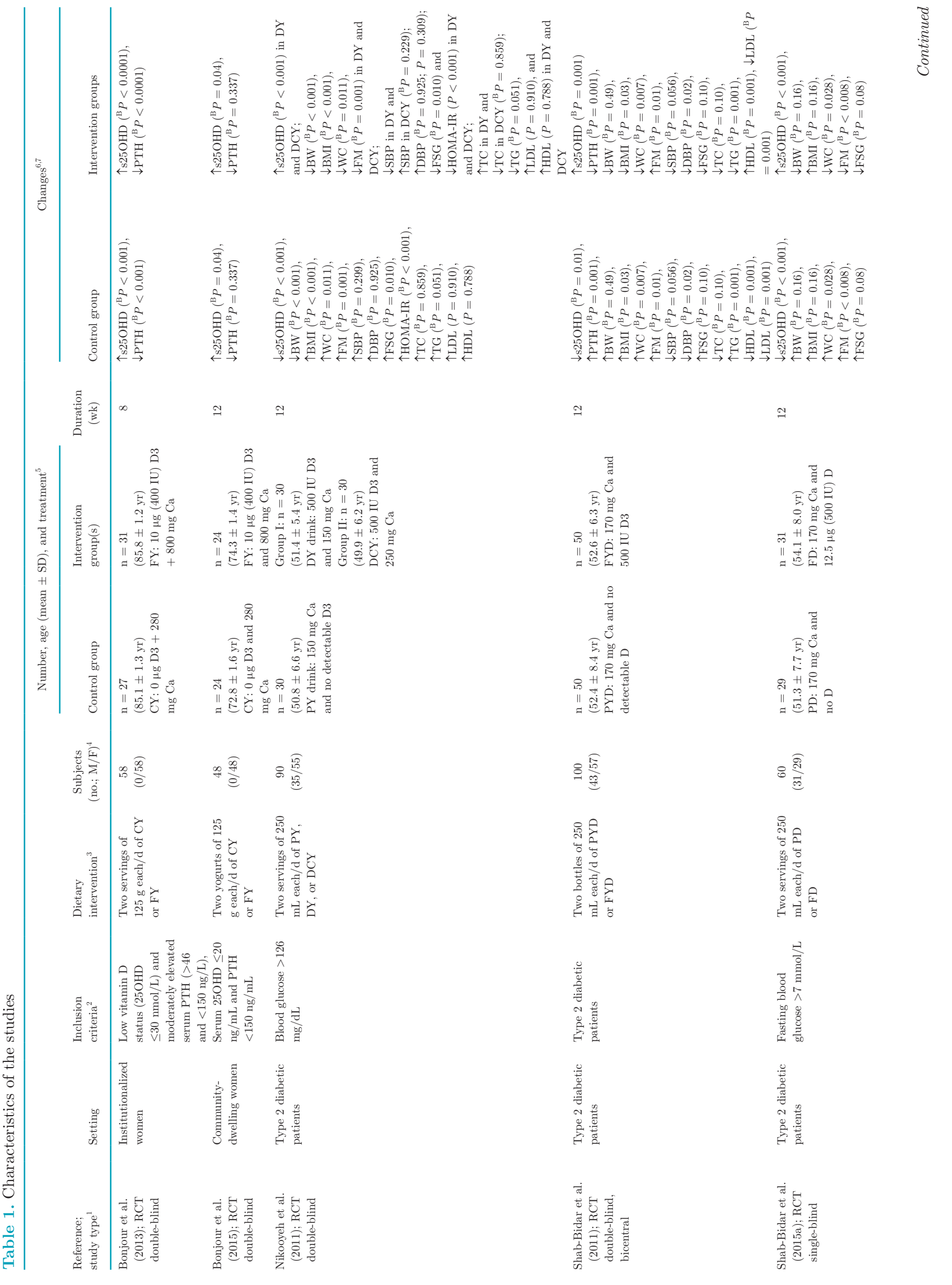




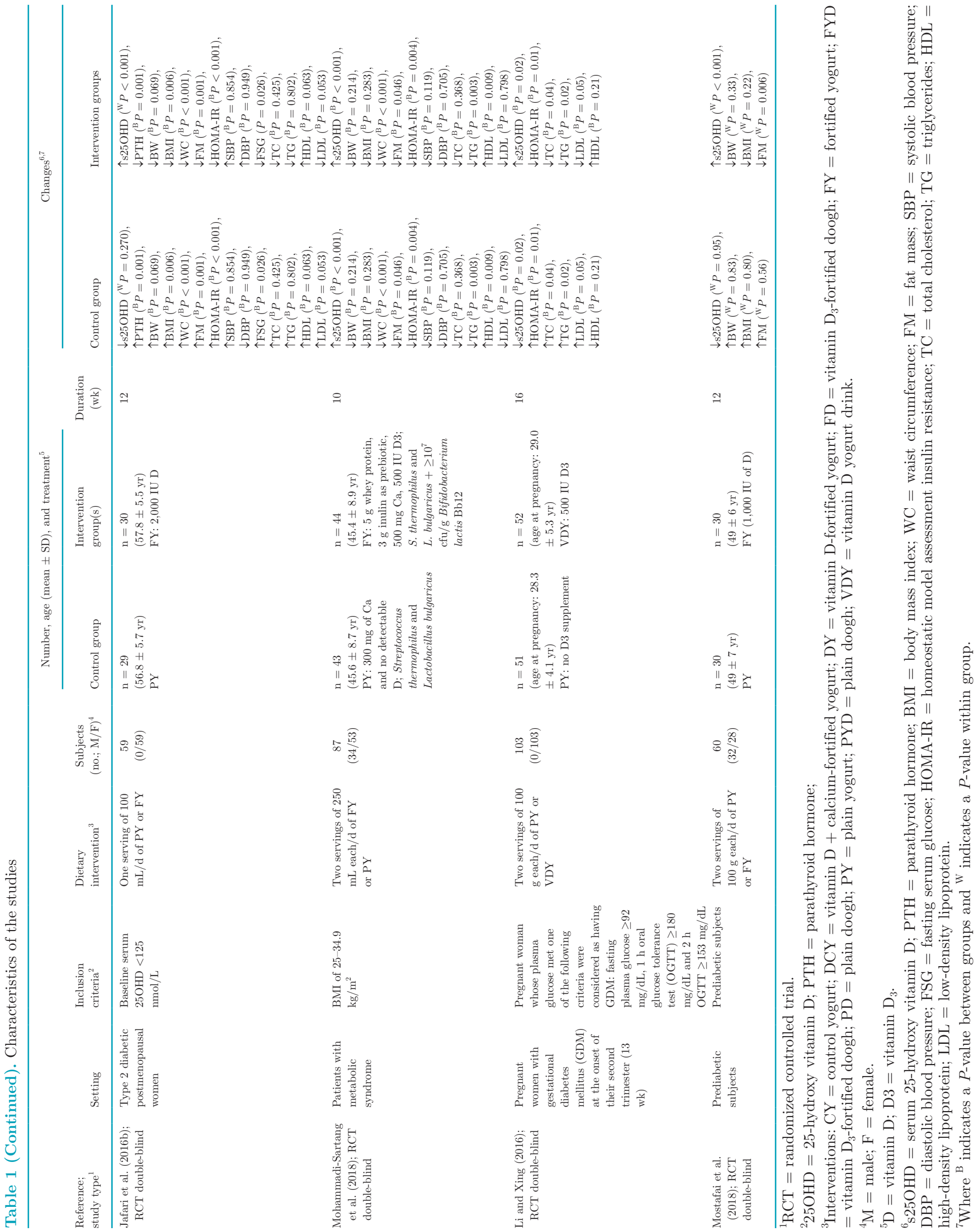




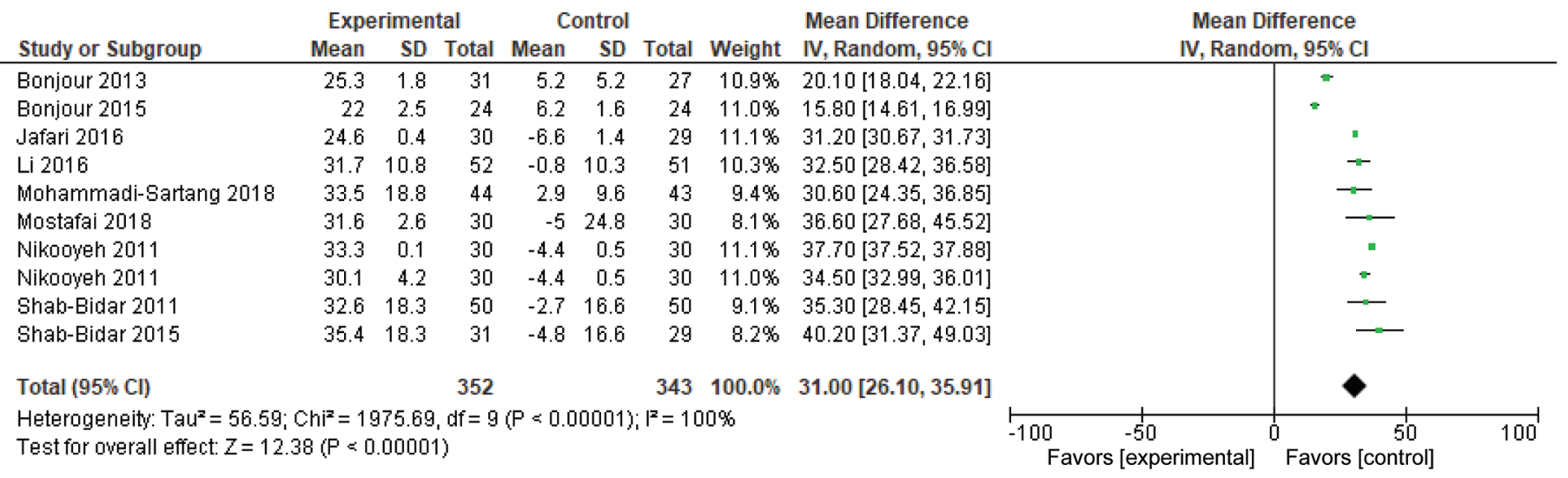

Figure 2. Forest plots for randomized controlled trials of vitamin D-fortified yogurt studies included in serum 25-hydroxy vitamin D $(\mathrm{nmol} / \mathrm{L})$ subgroup meta-analysis $(\mathrm{n}=659)$. Studies are listed by first author and year. $\mathrm{IV}=$ equation that can be estimated by inverse variance (linear, exponential). The square represents the measure of effect (i.e., an odds ratio) for each study; the area of each square is proportional to the study's weight in the meta-analysis. Horizontal lines represent confidence intervals. The diamond represents the meta-analyzed measure of effect; the lateral points of the diamond indicate confidence intervals for this estimate. The vertical line represents no effect; if the confidence interval for an individual study overlaps with this line, the given level of confidence for the effect size does not differ from no effect for that study.

from 11.33 to $21.50 \mathrm{ng} / \mathrm{L}$ depending on the study $(P<$ $0.05)$. One trial showed a nonsignificant reduction in PTH level in the intervention group compared with the control group (Bonjour et al., 2015).

Changes in Lipid Profile. Three clinical studies reported a statistically significant reduction in triglyceride levels, ranging from 29.7 to $63.2 \mathrm{mg} / \mathrm{dL}(P<0.05$; Shab-Bidar et al., 2011; Li and Xing, 2016; Mohammadi-Sartang et al., 2018), and 2 studies showed nonsignificant changes in triglycerides $[P=0.051$ (Nikooyeh et al., 2011); $P=0.802$ (Jafari et al., 2016b)]. One study demonstrated a significant decrease in total cholesterol in the intervention group compared with the control group ( $44.4 \mathrm{mg} / \mathrm{dL}, P=0.04 ; \mathrm{Li}$ and Xing, 2016). One study demonstrated a significant decrease in total cholesterol in the intervention group compared with the control group $(44.4 \mathrm{mg} / \mathrm{dL}, P=0.04$; Shab-Bidar et al., 2011) and 2 studies showed significant increases in HDL fraction in the intervention group versus the con- trol group (2.7 and $3 \mathrm{mg} / \mathrm{dL}, P=0.001$; Shab-Bidar et al., 2011; Mohammadi-Sartang et al., 2018). Four studies showed nonsignificant changes in LDL $[P=$ 0.910 (Nikooyeh et al., 2011); $P=0.053$ (Jafari et al., 2016b); $P=0.798$ (Mohammadi-Sartang et al., 2018); $P=0.05$ ( $\mathrm{Li}$ and Xing, 2016)] and HDL cholesterol fractions $[P=0.788$ (Nikooyeh et al., 2011); $P=0.063$ (Jafari et al., 2016b); $P=0.535$ (Mohammadi-Sartang et al., 2018); $P=0.21$ ( $\mathrm{Li}$ and Xing, 2016)] in the intervention groups compared with the control groups.

Changes in Blood Pressure. Four studies reported nonsignificant changes in diastolic blood pressure $[P=$ 0.925 (Nikooyeh et al., 2011); $P=0.949$ (Jafari et al., 2016b); $P=0.705$ (Mohammadi-Sartang et al., 2018); $P=$ not evaluated (Shab-Bidar et al., 2011) ] and systolic blood pressure $(P=0.299$ (Nikooyeh et al., 2011); $P=0.056$ (Shab-Bidar et al., 2011); $P=0.854$ (Jafari et al., 2016b); $P=0.119$ (Mohammadi-Sartang et al., 2018)].

\begin{tabular}{|c|c|c|c|c|c|c|c|c|c|c|c|c|}
\hline \multirow[b]{2}{*}{ Study or Subgroup } & \multicolumn{3}{|c|}{ Experimental } & \multicolumn{3}{|c|}{ Control } & \multicolumn{3}{|c|}{ Mean Difference } & \multirow{2}{*}{\multicolumn{2}{|c|}{$\begin{array}{c}\text { Mean Difference } \\
\text { IV, Random, } 95 \% \mathrm{Cl}\end{array}$}} & \\
\hline & Mean & SD & Total & Mean & SD & Total & Weight & IV, Random, $95 \% \mathrm{Cl}$ & & & & \\
\hline Bonjour 2013 & -28.6 & 7.2 & 31 & -7.1 & 2.9 & 27 & $29.7 \%$ & $-21.50[-24.26,-18.74]$ & & 둘 & & \\
\hline Bonjour 2015 & -16.7 & 2.9 & 24 & -2.8 & 2.7 & 24 & $32.1 \%$ & $-13.90[-15.49,-12.31]$ & & - & & \\
\hline Jafari 2016 & -8.2 & 3.2 & 30 & 3.2 & 2 & 29 & $32.5 \%$ & $-11.40[-12.76,-10.04]$ & & घ & & \\
\hline Shab-Bidar 2011 & -11.7 & 20.6 & 50 & 4.3 & 58.3 & 50 & $5.7 \%$ & $-16.00[-33.14,1.14]$ & & & & \\
\hline Total $(95 \% \mathrm{Cl})$ & & & 135 & & & 130 & $100.0 \%$ & $-15.47[-19.97,-10.96]$ & & & & \\
\hline $\begin{array}{l}\text { Heterogeneity: Tau² } \\
\text { Test for overall effect }\end{array}$ & $\begin{array}{l}15.81 ; 0 \\
Z=6.73\end{array}$ & $\begin{array}{l}h i^{2}= \\
(P \leq D\end{array}$ & $\begin{array}{l}1.77, \mathrm{~d} \\
.00001\end{array}$ & $f=3(\mathrm{~F}$ & $=0.0$ & $01) ; F$ & $=93 \%$ & & -1 & -50 & $\begin{array}{lc}0 & 50 \\
& \text { Favors [controll }\end{array}$ & 100 \\
\hline
\end{tabular}

Figure 3. Forest plots for randomized controlled trials of vitamin D-fortified yogurt studies included in parathyroid hormone (ng/L) subgroup meta-analysis $(\mathrm{n}=265)$. Studies are listed by first author and year. IV = equation that can be estimated by inverse variance (linear, exponential). The square represents the measure of effect (i.e., an odds ratio) for each study; the area of each square is proportional to the study's weight in the meta-analysis. Horizontal lines represent confidence intervals. The diamond represents the meta-analyzed measure of effect; the lateral points of the diamond indicate confidence intervals for this estimate. The vertical line represents no effect; if the confidence interval for an individual study overlaps with this line, the given level of confidence for the effect size does not differ from no effect for that study. 


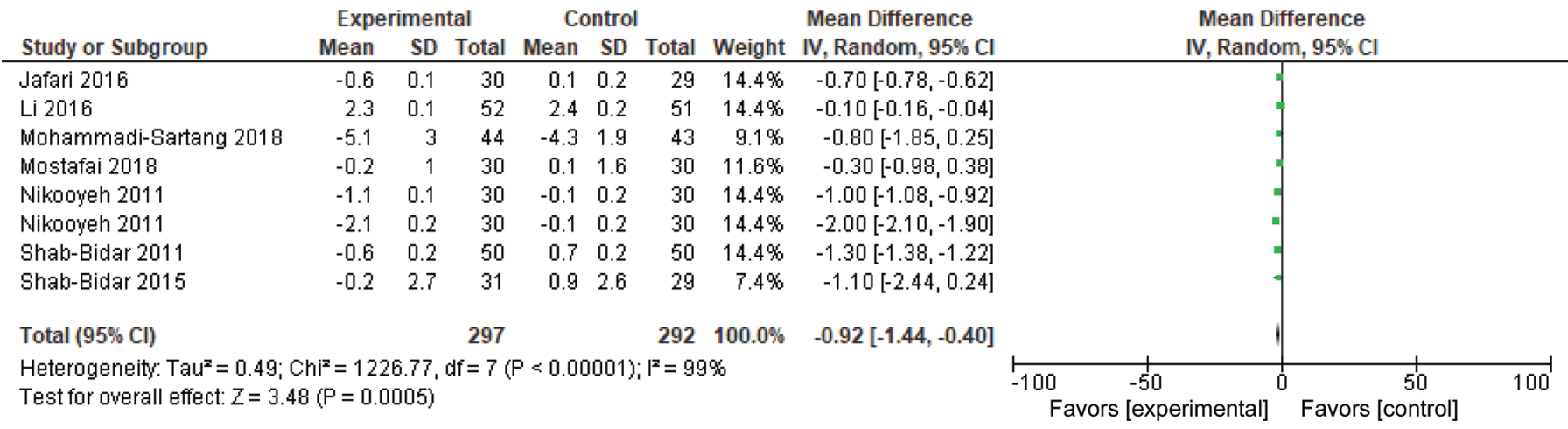

Figure 4. Forest plots for randomized controlled trials of vitamin D-fortified yogurt studies included in BW (kg) subgroup meta-analysis (n $=589$ ). Studies are listed by first author and year. IV = equation that can be estimated by inverse variance (linear, exponential). The square represents the measure of effect (i.e., an odds ratio) for each study; the area of each square is proportional to the study's weight in the metaanalysis. Horizontal lines represent confidence intervals. The diamond represents the meta-analyzed measure of effect; the lateral points of the diamond indicate confidence intervals for this estimate. The vertical line represents no effect; if the confidence interval for an individual study overlaps with this line, the given level of confidence for the effect size does not differ from no effect for that study.

Changes in HOMA-IR. Four studies demonstrated a significant decrease in HOMA-IR in the intervention groups compared with the control groups (Nikooyeh et al., 2011; Jafari et al., 2016b; Li and Xing, 2016; Mohammadi-Sartang et al., 2018). The range of decrease was from 1.0 to 2.8 units $(P<0.05)$ in subjects who consumed fortified yogurt compared with those who did not.

Changes in Fasting Serum Glucose. Two studies demonstrated a statistically significant decrease of fasting serum glucose (FSG) in the intervention groups compared with the control groups (Nikooyeh et al., 2011; Jafari et al., 2016b). The decreases ranged from 5.3 to $26.0 \mathrm{mg} / \mathrm{dL}(P<0.05)$ in subjects who consumed fortified yogurt compared with those who did not. Two studies reported nonsignificant changes in FSG $[P=$ 0.10 (Shab-Bidar et al., 2011); $P=0.08$ (Shab-Bidar et al., 2015a)].

\section{Considering Different Anthropometric Outcomes}

Changes in $B W$. Among the studies considered, only one showed a statistically significant reduction in BW of $1.00 \mathrm{~kg}(P<0.001)$ in the intervention group compared with the control group (Nikooyeh et al., 2011). Other studies reported similar decreases in BW, although the results were not significant $[P=0.49$ (Shab-Bidar et al., 2011); $P=0.16$ (Shab-Bidar et al., 2015a); $P=0.069$ (Jafari et al., 2016b); $P=0.214$ (Mohammadi-Sartang et al., 2018); $P=$ NE (Mostafai et al., 2018)].

Changes in BMI. Three studies demonstrated a significant decrease in the intervention group, ranging from 0.4 to $0.6 \mathrm{~kg} / \mathrm{m}^{2}(P<0.05$; Nikooyeh et al., 2011; Shab-Bidar et al., 2011; Jafari et al., 2016b). In contrast, 3 studies indicated that subjects that consumed fortified yogurt had a nonsignificant decrease in

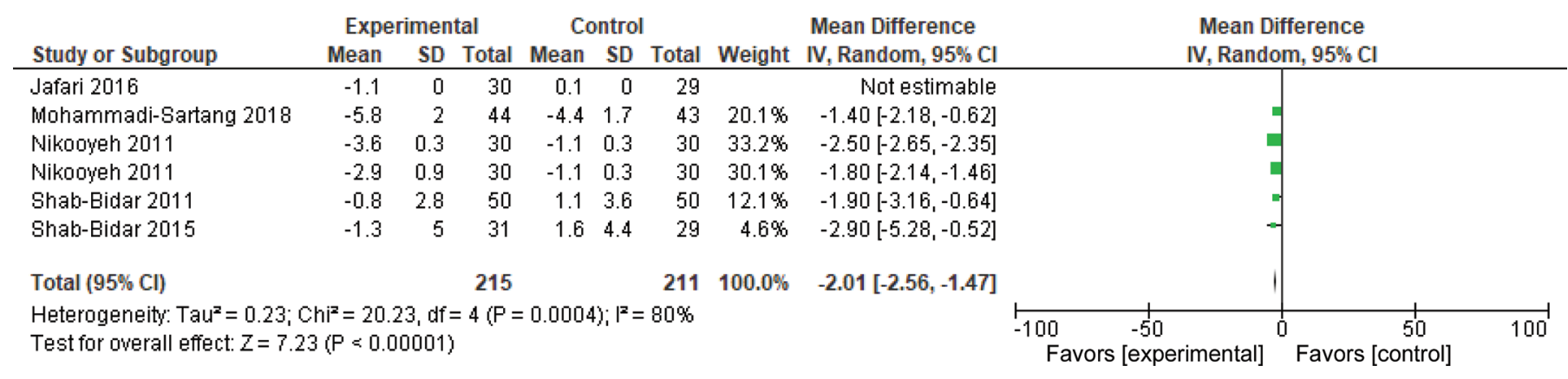

Figure 5. Forest plots for randomized controlled trials of vitamin D-fortified yogurt studies included in waist circumference (cm) subgroup meta-analysis $(\mathrm{n}=426)$. Studies are listed by first author and year. IV = equation that can be estimated by inverse variance (linear, exponential). The square represents the measure of effect (i.e., an odds ratio) for each study; the area of each square is proportional to the study's weight in the meta-analysis. Horizontal lines represent confidence intervals. The diamond represents the meta-analyzed measure of effect; the lateral points of the diamond indicate confidence intervals for this estimate. The vertical line represents no effect; if the confidence interval for an individual study overlaps with this line, the given level of confidence for the effect size does not differ from no effect for that study. 


\begin{tabular}{|c|c|c|c|c|c|c|c|c|c|c|c|}
\hline \multirow[b]{2}{*}{ Study or Subgroup } & \multicolumn{3}{|c|}{ Experimental } & \multicolumn{3}{|c|}{ Control } & \multicolumn{2}{|r|}{ Mean Difference } & \multirow{2}{*}{\multicolumn{3}{|c|}{$\begin{array}{c}\text { Mean Difference } \\
\text { IV, Random, } 95 \% \mathrm{Cl}\end{array}$}} \\
\hline & Mean & SD & Total & Mean & SD & Total & Weight & IV, Random, $95 \% \mathrm{Cl}$ & & & \\
\hline Jafari 2016 & -0.2 & 0 & 30 & 0.3 & 0 & 29 & & Not estimable & & & \\
\hline Wohammadi-Sartang 2018 & -1.8 & 1.2 & 44 & $-1 . \overline{6}$ & 0.8 & 43 & $16.9 \%$ & $-0.20[-0.63,0.23]$ & & & \\
\hline Mostafai 2018 & -0.1 & 0.4 & 30 & 0 & 0.6 & 30 & $44.9 \%$ & $-0.10[-0.36,0.16]$ & & & \\
\hline Nikooyeh 2011 & -0.5 & 0 & 30 & 0.1 & 0 & 30 & & Not estimable & & & \\
\hline Nikooyeh 2011 & -0.9 & 0 & 30 & 0.1 & 0 & 30 & & Not estimable & & & \\
\hline Shab-Bidar 2011 & -0.2 & 1.4 & 50 & 0.3 & 0.9 & 50 & $14.5 \%$ & $-0.50[-0.96,-0.04]$ & & & \\
\hline Shab-Bidar 2015 & 0.2 & 0.6 & 31 & 0.2 & 0.8 & 29 & $23.7 \%$ & $0.00[-0.36,0.36]$ & & & \\
\hline Total $(95 \% \mathrm{Cl})$ & & & 245 & & & 241 & $100.0 \%$ & $-0.15[-0.33,0.03]$ & & & \\
\hline $\begin{array}{l}\text { Heterogeneity: } \operatorname{Tau}^{2}=0.00 ; 0 \\
\text { Test for owerall effect: } Z=1.6\end{array}$ & $\begin{array}{l}P=3.0 \\
P=0.0\end{array}$ & wi & $(P=0$ & $0.38) ; 1^{2}$ & $=2 \%$ & & & & $\begin{array}{ll}-100 & -50 \\
\text { Favors [experimental] }\end{array}$ & Favors [control] & $100^{\circ}$ \\
\hline
\end{tabular}

Figure 6. Forest plots for randomized controlled trials of vitamin D-fortified yogurt studies included in body mass index $\left(\mathrm{kg} / \mathrm{m}^{2}\right) \mathrm{subgroup}$ meta-analysis $(\mathrm{n}=486)$. Studies are listed by first author and year. IV = equation that can be estimated by inverse variance (linear, exponential). The square represents the measure of effect (i.e., an odds ratio) for each study; the area of each square is proportional to the study's weight in the meta-analysis. Horizontal lines represent confidence intervals. The diamond represents the meta-analyzed measure of effect; the lateral points of the diamond indicate confidence intervals for this estimate. The vertical line represents no effect; if the confidence interval for an individual study overlaps with this line, the given level of confidence for the effect size does not differ from no effect for that study.

BMI $[P=0.16$ (Shab-Bidar et al., 2015a); $P=0.283$ (Mohammadi-Sartang et al., 2018); $P=$ NE (Mostafai et al., 2018)].

Changes in Waist Circumference. Five studies (Nikooyeh et al., 2011; Shab-Bidar et al., 2011, 2015a; Jafari et al., 2016b; Mohammadi-Sartang et al., 2018) found a significant reduction in waist circumference in the intervention group compared with the control groups, with decreases ranging from 1.2 to $2.9 \mathrm{~cm}(P$ $<0.05)$.

Changes in Fat Mass. Contrasting significant results were found. Although 4 studies found significant reductions in the intervention groups compared with the control groups, ranging from 1.3 to $3.6 \%$ ( $P$ $<$ 0.05; Nikooyeh et al., 2011; Shab-Bidar et al., 2015a; Jafari et al., 2016b; Mohammadi-Sartang et al., 2018), one study (Shab-Bidar et al., 2011) demonstrated an increase $(2.1 \%, P=0.01)$ and one did not report the $P$-value between the groups (Mostafai et al., 2018).

\section{Meta-Analyzed Data}

The meta-analyzed mean differences for random effects (MD) showed a significant statistically increase in 25OHD (MD $=+31.00 \mathrm{nmol} / \mathrm{L}$; 95\% CI: 26.10 to 35.91; $P<0.00001 ;$ Figure 2). In the 9 studies [Nikooyeh et al., 2011 (2 intervention groups: plain yogurt drink vs. vitamin D-fortified yogurt drink and plain yogurt drink vs. vitamin D plus calcium-fortified yogurt drink); Shab-Bidar et al., 2011; Bonjour et al., 2013, 2015; Shab-Bidar et al., 2015a; Jafari et al., 2016b; Li and Xing, 2016; Mohammadi-Sartang et al., 2018; Mostafai et al., 2018] with a total of 695 subjects (352 in the intervention group and 343 in the control group), the test for heterogeneity indicated that the treatment effect was significantly different between the considered studies; heterogeneity: $\tau^{2}$ (estimate of the between-studies variance in a random-effects meta-analysis $)=56.59 ; \chi^{2}$ $=1975.69, \mathrm{df}=9(P<0.00001) ; \boldsymbol{I}^{2}$ (statistic describ-

\begin{tabular}{|c|c|c|c|c|c|c|c|c|c|c|c|}
\hline \multirow[b]{2}{*}{ Study or Subgroup } & \multicolumn{3}{|c|}{ Experimental } & \multicolumn{3}{|c|}{ Control } & \multicolumn{2}{|r|}{ Mean Difference } & \multirow{2}{*}{\multicolumn{3}{|c|}{$\begin{array}{c}\text { Mean Difference } \\
\text { IV, Random, } 95 \% \mathrm{Cl}\end{array}$}} \\
\hline & Mean & SD & Total & Mean & SD & Total & Weight & IV, Random, $95 \% \mathrm{Cl}$ & & & \\
\hline Jafari 2016 & -29 & 0.3 & 30 & 0.7 & 0 & 29 & & Not estimable & & & \\
\hline Mohammadi-Sartang 2018 & -3 & 2.8 & 44 & -1.7 & 3.2 & 43 & $19.6 \%$ & $-1.30[-2.56,-0.04]$ & & & \\
\hline Mostafai 2018 & -0.8 & 1.5 & 30 & 0.2 & 1.6 & 30 & $21.1 \%$ & $-1.00[-1.78,-0.22]$ & & & \\
\hline Nikooyeh 2011 & -2.1 & 0.5 & 30 & 1.2 & 0.6 & 30 & $22.1 \%$ & $-3.30[-3.58,-3.02]$ & - & & \\
\hline Nikooyeh 2011 & -1 & 0 & 30 & 1.2 & 0.6 & 30 & & Not estimable & & & \\
\hline Shab-Bidar 2011 & 1.1 & 3 & 50 & -1 & 5.3 & 50 & $18.0 \%$ & $2.10[0.41,3.79]$ & & & \\
\hline Shab-Bidar 2015 & -1.9 & 2 & 31 & 0.6 & 3.3 & 29 & $19.2 \%$ & $-2.50[-3.89,-1.11]$ & 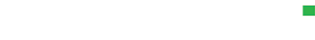 & & \\
\hline Total $(95 \% \mathrm{Cl})$ & & & 245 & & & 241 & $100.0 \%$ & $-1.30[-2.95,0.35]$ & & & \\
\hline $\begin{array}{l}\text { Heterogeneity: } \operatorname{Tau}^{2}=3.19 \\
\text { Test for overall effect: } Z=1.5\end{array}$ & $\begin{array}{l}P=70 \\
P=0\end{array}$ & $5, d f=$ & $4(\mathrm{P}=$ & $=0.000$ & $\left.y_{i}\right|^{2}$ & $=94 \%$ & & & $\begin{array}{ll}-100 & -50 \\
\text { Favors [experimental] }\end{array}$ & $\begin{array}{c}50 \\
\text { Favors [control] }\end{array}$ & $100^{\circ}$ \\
\hline
\end{tabular}

Figure 7. Forest plots for randomized controlled trials of vitamin D-fortified yogurt studies included in fat mass (percentage) subgroup metaanalysis $(\mathrm{n}=486)$. Studies are listed by first author and year. IV = equation that can be estimated by inverse variance (linear, exponential) The square represents the measure of effect (i.e., an odds ratio) for each study; the area of each square is proportional to the study's weight in the meta-analysis. Horizontal lines represent confidence intervals. The diamond represents the meta-analyzed measure of effect; the lateral points of the diamond indicate confidence intervals for this estimate. The vertical line represents no effect; if the confidence interval for an individual study overlaps with this line, the given level of confidence for the effect size does not differ from no effect for that study. 


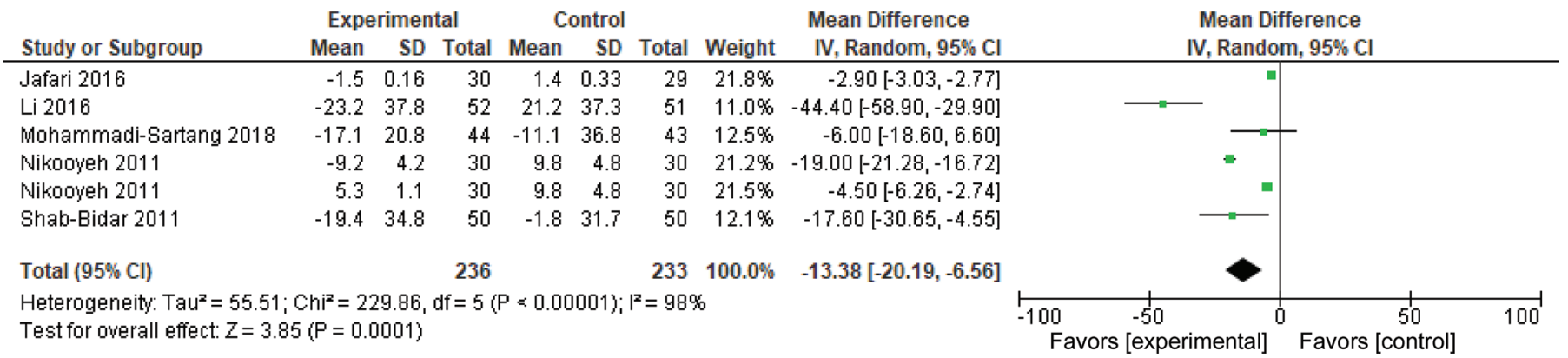

Figure 8. Forest plots for randomized controlled trials of vitamin D-fortified yogurt studies included in total cholesterol (mg/dL) subgroup meta-analysis $(\mathrm{n}=469)$. Studies are listed by first author and year. IV = equation that can be estimated by inverse variance (linear, exponential). The square represents the measure of effect (i.e., an odds ratio) for each study; the area of each square is proportional to the study's weight in the meta-analysis. Horizontal lines represent confidence intervals. The diamond represents the meta-analyzed measure of effect; the lateral points of the diamond indicate confidence intervals for this estimate. The vertical line represents no effect; if the confidence interval for an individual study overlaps with this line, the given level of confidence for the effect size does not differ from no effect for that study.

ing the percentage of variation across studies that is due to heterogeneity) $=100 \%$.

In 4 studies (Bonjour et al., 2013, 2015; Shab-Bidar et al., 2015a; Jafari et al., 2016b) considering PTH as the outcome variable with 265 subjects (135 in the intervention group and 130 in the control group), there was a significant decrease in PTH (Figure 3) in intervention groups compared with control groups $[\mathrm{MD}=$ $-15.47 \mathrm{ng} / \mathrm{L} ; 95 \%$ CI: -19.97 to $-10.96 ; P<0.00001$; heterogeneity: $\tau^{2}=15.81 ; \chi^{2}=41.77, \mathrm{df}=3(P<$ 0.00001); $\left.I^{2}=93 \%\right]$.

Regarding anthropometric parameters, in 7 studies (Nikooyeh et al., 2011, 2 intervention groups; ShabBidar et al., 2011, 2015a; Jafari et al., 2016b; Li and Xing, 2016; Mohammadi-Sartang et al., 2018; Mostafai et al., 2018) totaling 589 participants (297 in the intervention group and 292 in the control group), there was a significant decrease in BW (Figure 4) in intervention groups compared with control groups $[\mathrm{MD}=-0.92 \mathrm{~kg}$; 95\% CI: -1.44 to $-0.40 ; P=0.005$; heterogeneity: $\tau^{2}$ $\left.=0.49 ; \chi^{2}=1226.77, \mathrm{df}=7(P<0.00001) ; I^{2}=99 \%\right]$.
Five studies (Nikooyeh et al., 2011, 2 intervention groups; Shab-Bidar et al., 2011, 2015a; Jafari et al., 2016b; Mohammadi-Sartang et al., 2018) with a total of 426 subjects (215 in the intervention group and 211 in the control group) showed a significant decrease in waist circumference (Figure 5) in intervention groups compared with control groups $[\mathrm{MD}=-2.01 \mathrm{~cm} ; 95 \%$ CI: -2.56 to $-1.47 ; P<0.00001$; heterogeneity: $\tau^{2}=$ $\left.0.23 ; \chi^{2}=20.23, \mathrm{df}=4(P=0.0004) ; I^{2}=80 \%\right]$.

In 6 studies (Nikooyeh et al., 2011, 2 intervention groups; Shab-Bidar et al., 2011, 2015a; Jafari et al., 2016b; Mohammadi-Sartang et al., 2018; Mostafai et al., 2018) concerning BMI (Figure 6) and fat mass (Figure 7) with a total of 486 participants ( 245 in intervention group and 241 in control group), the meta-analysis did not find significant changes in the subjects who consumed fortified yogurt versus those who did not.

For the 5 studies (Nikooyeh et al., 2011, 2 intervention groups; Shab-Bidar et al., 2011; Jafari et al., 2016b; Mohammadi-Sartang et al., 2018) that evaluated lipid profile (469 subjects; 236 in intervention group

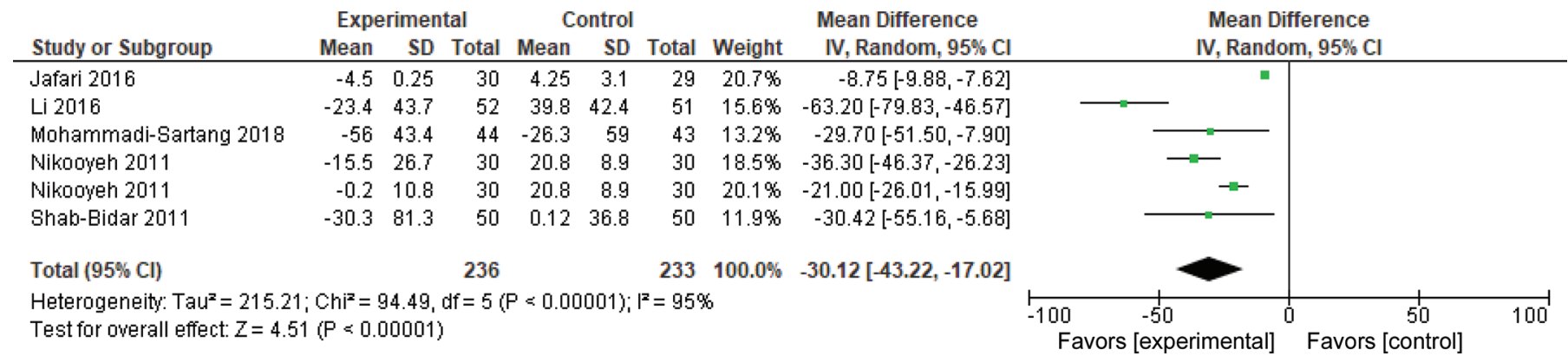

Figure 9. Forest plots for randomized controlled trials of vitamin D-fortified yogurt studies included in triglycerides (mg/dL) subgroup metaanalysis $(\mathrm{n}=469)$. Studies are listed by first author and year. IV = equation that can be estimated by inverse variance (linear, exponential). The square represents the measure of effect (i.e., an odds ratio) for each study; the area of each square is proportional to the study's weight in the meta-analysis. Horizontal lines represent confidence intervals. The diamond represents the meta-analyzed measure of effect; the lateral points of the diamond indicate confidence intervals for this estimate. The vertical line represents no effect; if the confidence interval for an individual study overlaps with this line, the given level of confidence for the effect size does not differ from no effect for that study. 


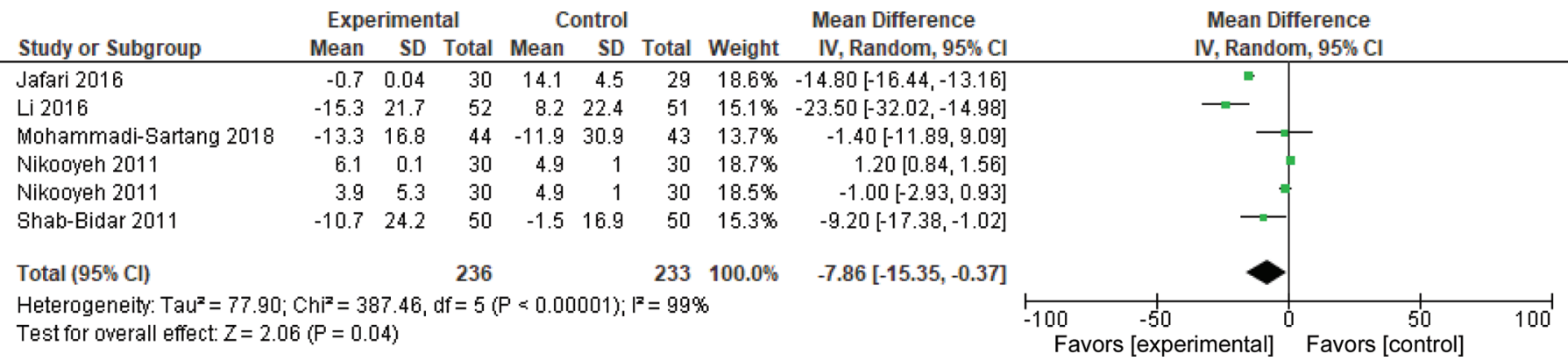

Figure 10. Forest plots for randomized controlled trials of vitamin D-fortified yogurt studies included in low-density lipoprotein cholesterol $(\mathrm{mg} / \mathrm{dL})$ subgroup meta-analysis $(\mathrm{n}=469)$. Studies are listed by first author and year. $\mathrm{IV}=$ equation that can be estimated by inverse variance (linear, exponential). The square represents the measure of effect (i.e., an odds ratio) for each study; the area of each square is proportional to the study's weight in the meta-analysis. Horizontal lines represent confidence intervals. The diamond represents the meta-analyzed measure of effect; the lateral points of the diamond indicate confidence intervals for this estimate. The vertical line represents no effect; if the confidence interval for an individual study overlaps with this line, the given level of confidence for the effect size does not differ from no effect for that study.

and 233 in control group), the meta-analysis showed a significant decrease in total cholesterol (Figure 8) $[\mathrm{MD}=-13.38 \mathrm{mg} / \mathrm{dL} ; 95 \% \mathrm{CI}:-20.19$ to $-6.56 ; P=$ 0.0001; heterogeneity: $\tau^{2}=55.51 ; \chi^{2}=229.86, \mathrm{df}=5$ $\left.(P<0.00001) ; I^{2}=98 \%\right]$ and triglycerides (Figure 9$)$ $[\mathrm{MD}=-30.12 \mathrm{mg} / \mathrm{dL} ; 95 \% \mathrm{CI}:-43.22$ to $-17.02 ; P$ $=0.00001 ;$ heterogeneity: $\tau^{2}=215.21 ; \chi^{2}=94.49, \mathrm{df}$ $\left.=5(P<0.00001) ; I^{2}=95 \%\right]$ in subjects consuming fortified yogurt.

As shown in Figure 10, we found a decrease in LDL cholesterol $[\mathrm{MD}=-7.86 \mathrm{mg} / \mathrm{dL} ; 95 \%$ CI: -15.35 to $-0.37 ; P=0.04$; heterogeneity: $\tau^{2}=77.90 ; \chi^{2}=387.46$, $\left.\mathrm{df}=5(P<0.00001) ; I^{2}=99 \%\right]$ in intervention groups compared with control groups. Increase in HDL cholesterol, however, was not significant $(P=0.08)$ when comparing results between the 2 groups (Figure 11).

In the 4 studies (Nikooyeh et al., 2011, 2 intervention groups; Jafari et al., 2016b; Li and Xing, 2016; Mohammadi-Sartang et al., 2018) that considered HOMA-IR as an outcome variable, with a total of 369 subjects (186 subjects in the intervention group and 183 subjects in the control group), there was a significant decrease in HOMA-IR (Figure 12) in intervention groups compared with control groups [MD $=-2.18$ units; $95 \%$ CI: -2.92 to -1.44 units; $P<0.00001$; heterogeneity: $\tau^{2}=0.38$; $\left.\chi^{2}=9.43, \mathrm{df}=3(P=0.02) ; I^{2}=68 \%\right]$.

The meta-analysis of 4 studies (Nikooyeh et al., 2011; 2 intervention groups; Shab-Bidar et al., 2011, 2015a; Jafari et al., 2016b) with a total 339 subjects (171 in the intervention group and 168 in the control group) showed a significant decrease in FSG (Figure 13) in the intervention group $(\mathrm{MD}=-22.54 \mathrm{mg} / \mathrm{dL} ; 95 \% \mathrm{CI}$ : -37.55 to $-7.52 ; P=0.003$; heterogeneity: $\tau^{2}=255.17$; $\left.\chi^{2}=356.52, \mathrm{df}=4(P<0.00001) ; I^{2}=99 \%\right)$.

The meta-analysis of 4 studies (Nikooyeh et al., 2011; 2 intervention groups; Shab-Bidar et al., 2011; Jafari et al., 2016b; Mohammadi-Sartang et al., 2018) with a total of 366 subjects (184 in the intervention group and 182 in the control group) showed no significant changes in systolic (Figure 14) or diastolic (Figure 15) blood

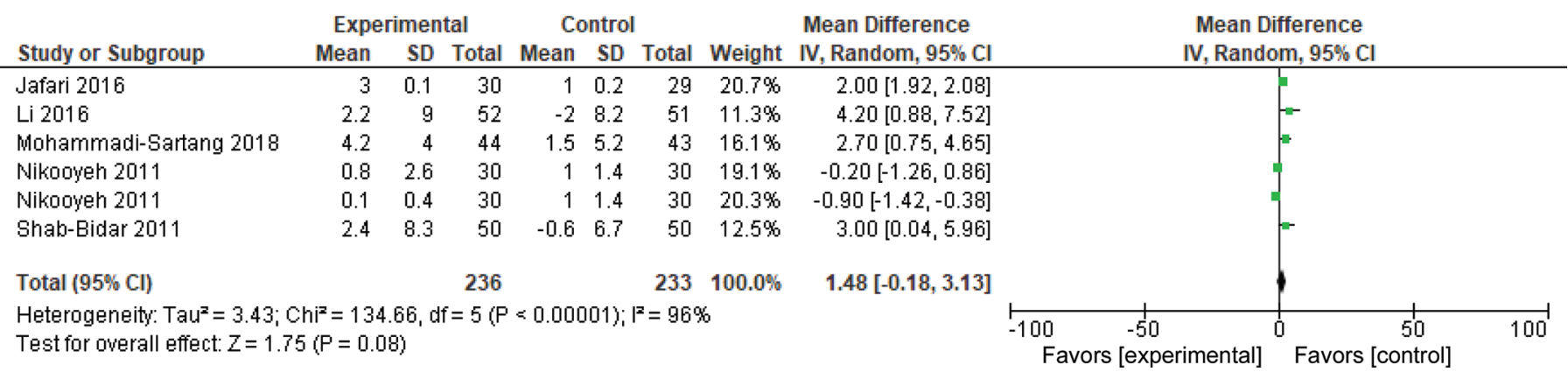

Figure 11. Forest plots for randomized controlled trials of vitamin D-fortified yogurt studies included in high-density lipoprotein cholesterol $(\mathrm{mg} / \mathrm{dL})$ subgroup meta-analysis $(\mathrm{n}=469)$. Studies are listed by first author and year. IV = equation that can be estimated by inverse variance (linear, exponential). The square represents the measure of effect (i.e., an odds ratio) for each study; the area of each square is proportional to the study's weight in the meta-analysis. Horizontal lines represent confidence intervals. The diamond represents the meta-analyzed measure of effect; the lateral points of the diamond indicate confidence intervals for this estimate. The vertical line represents no effect; if the confidence interval for an individual study overlaps with this line, the given level of confidence for the effect size does not differ from no effect for that study. 


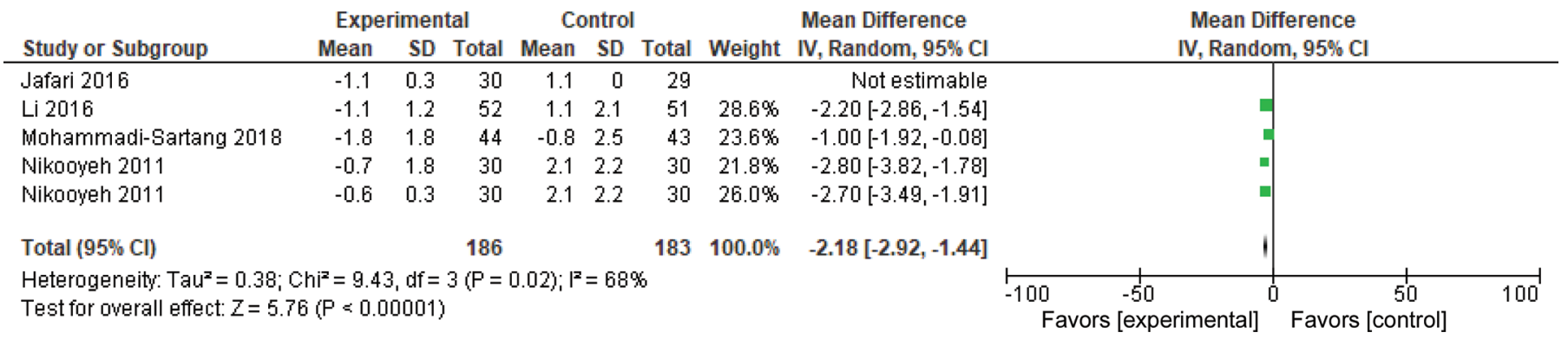

Figure 12. Forest plots for randomized controlled trials of vitamin D-fortified yogurt studies included in homeostatic model assessment insulin resistance (HOMA-IR) subgroup meta-analysis $(\mathrm{n}=369)$. Studies are listed by first author and year. IV = equation that can be estimated by inverse variance (linear, exponential). The square represents the measure of effect (i.e., an odds ratio) for each study; the area of each square is proportional to the study's weight in the meta-analysis. Horizontal lines represent confidence intervals. The diamond represents the meta-analyzed measure of effect; the lateral points of the diamond indicate confidence intervals for this estimate. The vertical line represents no effect; if the confidence interval for an individual study overlaps with this line, the given level of confidence for the effect size does not differ from no effect for that study.

pressure in subjects who consumed fortified yogurt versus those who did not $(P=0.35$ and $P=0.76)$.

\section{Risk of Bias}

No publication bias was indicated for any outcomes, as determined by funnel plot, Begg's test, and Egger's test $P$-values $>0.05$ (Table 2 ).

\section{DISCUSSION}

The systematic review and meta-analysis of $9 \mathrm{RCT}$ ( $\mathrm{n}=665$ participants), lasting between 8 and $16 \mathrm{wk}$, revealed a significant increase in serum 25OHD (31.00 $\mathrm{nmol} / \mathrm{L}$ ) as well as decreases in BW, waist circumference, HOMA-IR, FSG, total cholesterol, LDL cholesterol, and triglycerides after vitamin D (from 400 to 2,000 IU)-fortified yogurt supplementation in several cohorts, including pregnant women, adults, and elderly subjects with or without diabetes, prediabetes, or metabolic syndrome.
In addition, we found a decrease in PTH $(15.47 \mathrm{ng} / \mathrm{L})$ in subjects who consumed vitamin D-fortified yogurt. Parathyroid hormone values are inversely associated with 25OHD and begin to plateau in adults with serum 25OHD levels between 30 and $40 \mathrm{ng} / \mathrm{mL}$ (Chapuy et al., 1996; Holick et al., 2005). Vitamin D deficiency decreases the efficiency of intestinal absorption of dietary calcium and phosphorus, resulting in an increase in PTH (Heaney, 2004; Holick et al., 2005; Lips et al., 2006; Holick, 2007). Consequently, the decrease in PTH levels reported in the present work may be the result of increasing levels of circulating serum vitamin D.

Fortified foods, including milk, yogurt, butter, margarine, cheeses, orange juice, bread, and breakfast cereals, represent the major dietary sources of vitamin D. The effect of these foods on circulating 25OHD concentrations was evaluated in a recent meta-analysis (Black et al., 2012), in which the authors found an increase of $19.4 \mathrm{nmol} / \mathrm{L}$ in the levels of 25OHD.

Our findings showed a decrease in FSG $(-22.54 \mathrm{mg} /$ $\mathrm{dL}$, ) and HOMA-IR (-2.18) in subjects who consumed

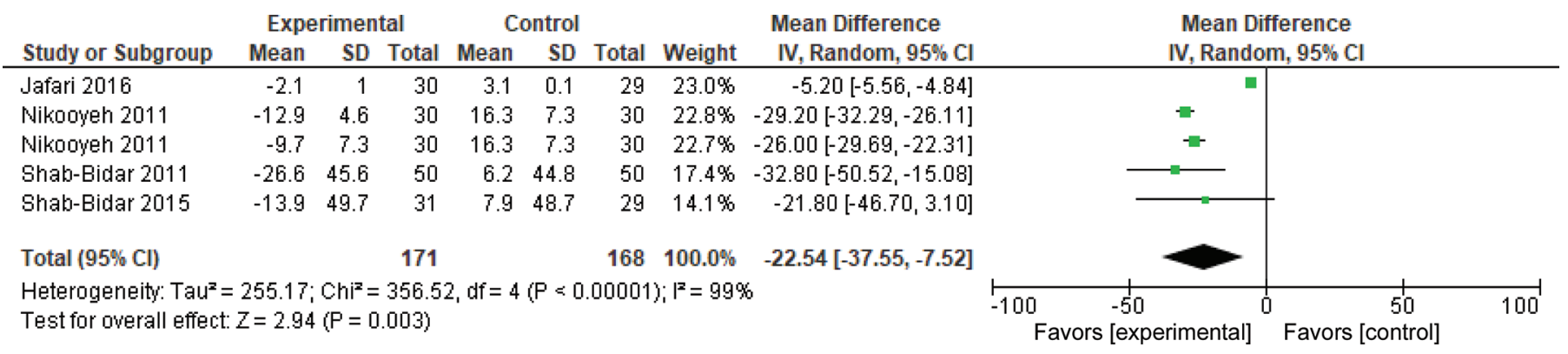

Figure 13. Forest plots for randomized controlled trials of vitamin D-fortified yogurt studies included in fasting serum glucose (mg/dL) subgroup meta-analysis $(\mathrm{n}=339)$. Studies are listed by first author and year. IV = equation that can be estimated by inverse variance (linear exponential). The square represents the measure of effect (i.e., an odds ratio) for each study; the area of each square is proportional to the study's weight in the meta-analysis. Horizontal lines represent confidence intervals. The diamond represents the meta-analyzed measure of effect; the lateral points of the diamond indicate confidence intervals for this estimate. The vertical line represents no effect; if the confidence interval for an individual study overlaps with this line, the given level of confidence for the effect size does not differ from no effect for that study. 


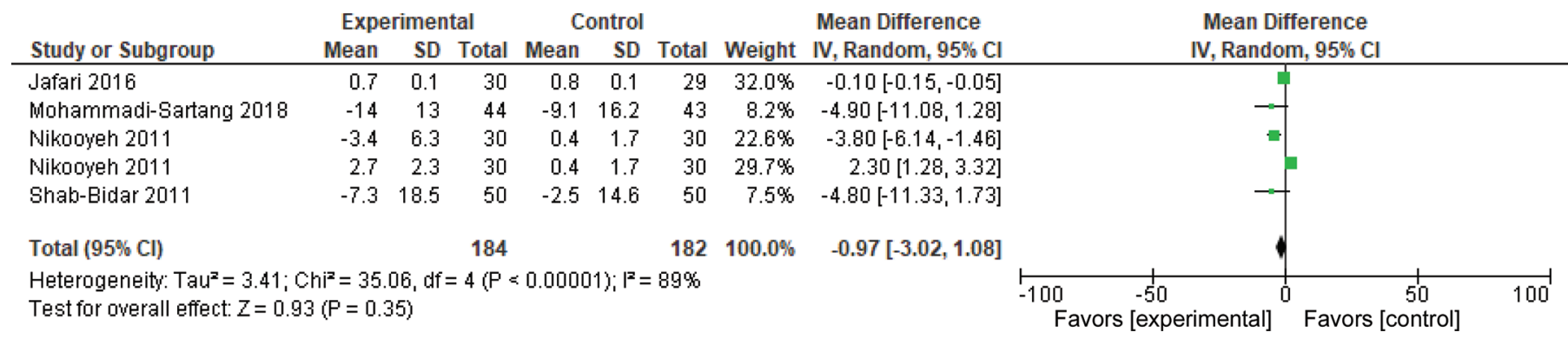

Figure 14. Forest plots for randomized controlled trials of vitamin D-fortified yogurt studies included in systolic blood pressure (mmHg) subgroup meta-analysis $(\mathrm{n}=366)$. Studies are listed by first author and year. IV = equation that can be estimated by inverse variance (linear, exponential). The square represents the measure of effect (i.e., an odds ratio) for each study; the area of each square is proportional to the study's weight in the meta-analysis. Horizontal lines represent confidence intervals. The diamond represents the meta-analyzed measure of effect; the lateral points of the diamond indicate confidence intervals for this estimate. The vertical line represents no effect; if the confidence interval for an individual study overlaps with this line, the given level of confidence for the effect size does not differ from no effect for that study.

yogurt supplemented with vitamin D. The hypothesis that yogurt intake protects against type 2 diabetes mellitus (T2DM) has recently been demonstrated by a meta-analysis (Gao et al., 2013). In addition, several lines of evidence support a role for vitamin D in pancreatic $\beta$-cell function. Existing meta-analyses that include the effects of vitamin D supplementation on glycemic control, however, concluded that there is currently insufficient evidence of a beneficial effect to recommend vitamin D (George et al., 2012).

Several mechanisms explain the effects of fortified yogurt containing calcium and vitamin D on T2DM. First, calcium provided by yogurt could decrease accumulation of body fat and accelerate BW and fat loss during energy restriction (Zemel, 2004). Second, calcium intake may increase fat oxidation and suppress adipose tissue oxidative and inflammatory stress, whereas adequate vitamin $\mathrm{D}$ may enhance the thermic effect of a meal and fat oxidation (Teegarden et al., 2008).

At the same time, a recent meta-analysis showed an inverse and significant association between circulat- ing 25OHD and risk of T2DM across a broad range of blood 25OHD levels in diverse populations (Song et al., 2013). The optimal 25OHD values for T2DM prevention remain unknown, but it seems likely that the combination of yogurt and vitamin D may improve the effects. In addition, 2 studies have evaluated the effect of vitamin D-fortified Persian yogurt drink (doogh) on oxidative stress (OS) in T2DM subjects. The first demonstrated an OS-attenuating effect of vitamin D. In particular, the results showed a significant decrement in serum protein carbonyl, serum cardiac myeloperoxidase, and advanced glycation end-products and a significant increment in superoxide dismutase (SOD) activity (Nikooyeh et al., 2014). The other study showed that improvement of vitamin D status via daily intake of fortified doogh ameliorated OS biomarkers in T2DM patients. Subjects who consumed fortified doogh (containing $170 \mathrm{mg}$ of calcium and $500 \mathrm{IU}$ of vitamin $\mathrm{D}_{3} / 250 \mathrm{~mL}$ ) for $12 \mathrm{wk}$ showed a significant increase in glutathione and decrease in malondialdehyde, but no change in serum SOD concentrations (Shab-Bidar et al., 2015b). Those studies confirmed the antioxidative

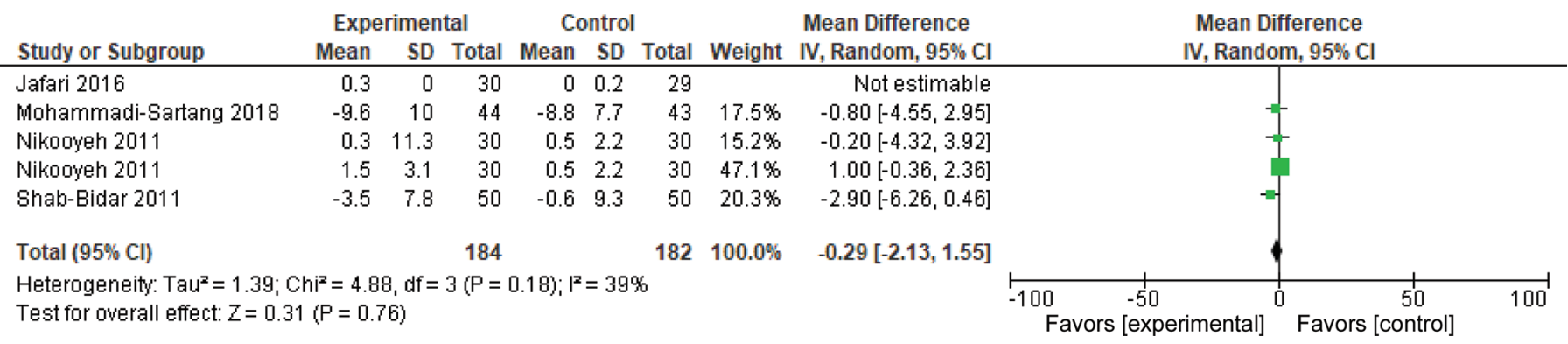

Figure 15. Forest plots for randomized controlled trials of vitamin D-fortified yogurt studies included in diastolic blood pressure (mmHg) subgroup meta-analysis $(\mathrm{n}=366)$. Studies are listed by first author and year. IV = equation that can be estimated by inverse variance (linear, exponential). The square represents the measure of effect (i.e., an odds ratio) for each study; the area of each square is proportional to the study's weight in the meta-analysis. Horizontal lines represent confidence intervals. The diamond represents the meta-analyzed measure of effect; the lateral points of the diamond indicate confidence intervals for this estimate. The vertical line represents no effect; if the confidence interval for an individual study overlaps with this line, the given level of confidence for the effect size does not differ from no effect for that study. 


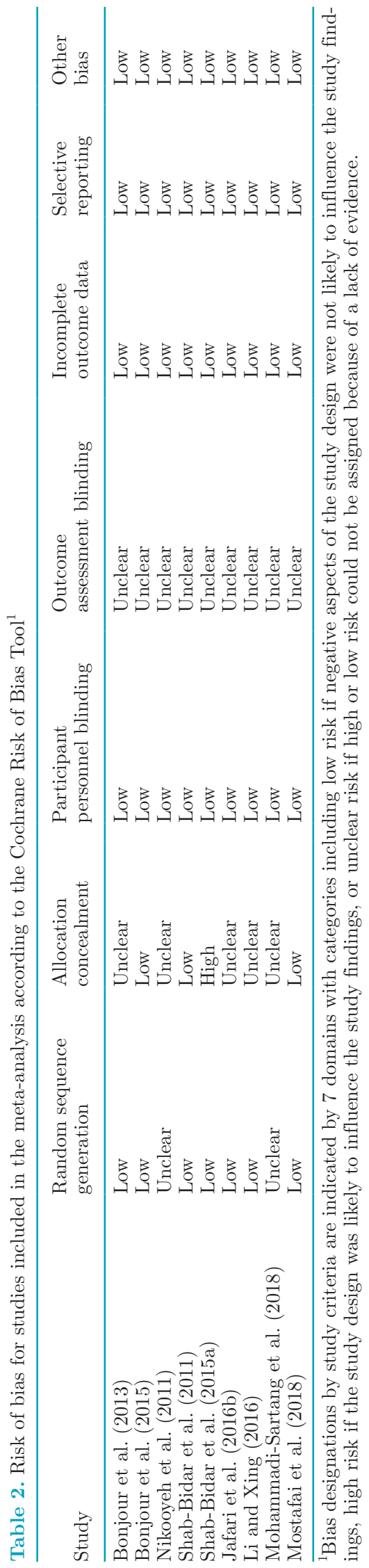

properties of vitamin $\mathrm{D}$, even when administered in the form of fortified yogurt.

Another key point highlighted in this study is the reduction in BW $(0.92 \mathrm{~kg})$ during the supplementation of vitamin D-fortified yogurt. This result is in line with a previous meta-analysis that demonstrated modest beneficial effects of consuming dairy products in facilitating weight loss in short-term or energyrestricted RCT (Chen et al., 2012). Our results were confirmed by the Framingham study, which suggests that further studies are needed to confirm the beneficial role of increasing total dairy and yogurt intake as part of a healthy and calorie-balanced dietary pattern, in the long-term prevention of gain in weight and waist circumference (Wang et al., 2014). Our finding can be justified by a recent meta-analysis indicating that a higher BMI may lead to lower 25OHD levels, and that any effects of lower 25OHD increasing BMI are likely to be small (Vimaleswaran et al., 2013). A possible explanation of our results is that vitamin D deficiency affects the composition of the intestinal microbiota (Ly et al., 2011). Although a small study suggested that decreased vitamin D intake was correlated with differences in fecal microbiota composition (Paxman et al., 2008), it is possible that the host's vitamin D status could modify the effect of the intestinal microbiota on the immune system. For instance, mice that lack the vitamin D receptor (VDR) develop chronic, low-grade inflammation in the gastrointestinal tract ( $\mathrm{Yu}$ et al., 2008).

Furthermore, our meta-analysis suggests that consuming vitamin D-fortified yogurt may explain the beneficial effect on lipid profile, including reductions in triglycerides $(30.12 \mathrm{mg} / \mathrm{dL})$, total cholesterol (13.38 $\mathrm{mg} / \mathrm{dL})$, and LDL cholesterol level $(7.86 \mathrm{mg} / \mathrm{dL})$, and an increase in HDL cholesterol, albeit not significant.

It is assumed that increased calcium intake reduces serum triglycerides by decreasing hepatic triglyceride formation or secretion (Cho et al., 2005), whereas vitamin D increases intestinal calcium absorption (Barger-Lux et al., 1995). According to Zittermann et al. (2009), the vitamin D-mediated reduction in serum triglycerides might be explained by the effect similar to oral calcium supplementation (increased amount of absorbed calcium). Decreasing concentrations of PTH are accompanied by a decrease in plasma post-heparin lipolytic activity (Lacour et al., 1982), and, consequently the reduction in serum PTH may have result in a decrease in serum triglycerides (Zittermann et al., 2009).

A recent meta-analysis by Wang et al. (2012) demonstrated a generally linear, inverse association between circulating 25OHD in the range of 20 to $60 \mathrm{nmol} / \mathrm{L}$ and risk of CVD. Blood pressure was shown to decrease in 
our meta-analysis, albeit not significantly; thus, current evidence is weak to support the small effect of vitamin $\mathrm{D}$ on blood pressure in studies of hypertensive patients (Witham et al., 2009) or the small effect of calcium supplementation in the diet on blood pressure in studies of both hypertensive and normotensive patients (Griffith et al., 1999). Moreover, all relevant Hill criteria for a causal association in a biological system are satisfied to indicate a low 25OHD level as a CVD risk factor (Weyland et al., 2014). The controversy stems from the fact that the meta-analysis performed by Elamin et al. (2011) indicated that recommending vitamin D to patients to reduce CVD risk is not consistent with current evidence, although a recent meta-analysis suggests that vitamin $\mathrm{D}$ supplementation may act to protect against CVD by improving risk factors, including high blood pressure, elevated PTH, dyslipidemia, and inflammation (Mirhosseini et al., 2018).

To our knowledge, this meta-analysis is the first to assess the efficacy of vitamin D-fortified yogurt supplementation within $\mathrm{RCT}$ on serum $25 \mathrm{OH}$ vitamin $\mathrm{D}$ levels, anthropometric measures, lipid profile, and glucose outcomes. Several limitations of the present study should be noted. First, the number of eligible studies was small. We evaluated the efficacy of vitamin Dfortified yogurt on weight loss and metabolic outcomes independent of researcher-imposed energy restriction or weight-loss counseling. Our findings may not be generalizable to healthy populations other than those investigated in the present study - patients with diagnosed chronic conditions (i.e., T2DM patients). In addition, in this meta-analysis, the interventions included vitamin D supplementation ranging from 400 to 2,000 IU. The main criticism, therefore, is that evaluations were not based on a fixed dose. The intervention period was different in each study and included a wide range of the population with regard to age, BMI, and health condition. Although our meta-analysis showed statistically significant changes in $25 \mathrm{OHD}$, PTH, BW, waist circumference, triglycerides, total and LDL cholesterol, HOMA-IR, and FSG following the consumption of vitamin D-fortified yogurt, the test for heterogeneity showed existing variability between studies in BMI, fat mass, blood pressure, and HDL cholesterol.

The present study also has several methodological strengths. Our analysis involved high-quality studies and rigorous exclusion criteria that reduced the presence of confounding variables such as a diagnosed disease and weight-loss counseling. A thorough assessment of study quality and bias was performed using validated methods, and we explored heterogeneity using a sensitivity analysis. In conclusion, because of the observed improvements in weight loss, glycemia, insulin, PTH, and lipid profile, vitamin D-fortified yogurt may be a feasible approach to improve metabolic health and weight in young and elderly subjects with or without diabetes, prediabetes, or metabolic syndrome. The findings reported here provide evidence that enhancing the vitamin $\mathrm{D}$ content of yogurt may benefit those at risk of developing chronic diseases, which has important implications for food regulators, food manufacturers, clinicians, and consumers alike.

\section{ACKNOWLEDGMENTS}

This research did not receive any specific grant from funding agencies in the public, commercial, or not-forprofit sectors. The authors declare that they have no conflicts of interest.

\section{REFERENCES}

Adolfsson, O., S. N. Meydani, and R. M. Russell. 2004. Yogurt and gut function. Am. J. Clin. Nutr. 80:245-256. https://doi.org/10 $.1093 /$ ajcn/80.2.245.

Baeke, F., T. Takiishi, H. Korf, C. Gysemans, and C. Mathieu. 2010. Vitamin D: Modulator of the immune system. Curr. Opin. Pharmacol. 10:482-496. https://doi.org/10.1016/j.coph.2010.04.001.

Barger-Lux, M. J., R. P. Heaney, S. J. Lanspa, J. C. Healy, and H. F. DeLuca. 1995. An investigation of sources of variation in calcium absorption efficiency. J. Clin. Endocrinol. Metab. 80:406-411. https://doi.org/10.1210/jcem.80.2.7852497.

Bischoff-Ferrari, H. A., B. Dawson-Hughes, H. B. Staehelin, J. E. Orav, A. E. Stuck, R. Theiler, J. B. Wong, A. Egli, D. P. Kiel, and J. Henschkowski. 2009. Fall prevention with supplemental and active forms of vitamin D: A meta-analysis of randomised controlled trials. BMJ 339:b3692. https://doi.org/10.1136/bmj.b3692.

Black, L. J., K. M. Seamans, K. D. Cashman, and M. Kiely. 2012. An updated systematic review and meta-analysis of the efficacy of vitamin D food fortification. J. Nutr. 142:1102-1108. https://doi .org/10.3945/jn.112.158014

Bonjour, J.-P., V. Benoit, S. Atkin, and S. Walrand. 2015. Fortification of yogurts with vitamin D and calcium enhances the inhibition of serum parathyroid hormone and bone resorption markers: A double blind randomized controlled trial in women over 60 living in a community dwelling home. J. Nutr. Health Aging 19:563-569. https://doi.org/10.1007/s12603-015-0498-8.

Bonjour, J.-P., V. Benoit, F. Payen, and M. Kraenzlin. 2013. Consumption of yogurts fortified in vitamin $\mathrm{D}$ and calcium reduces serum parathyroid hormone and markers of bone resorption: A double-blind randomized controlled trial in institutionalized elderly women. J. Clin. Endocrinol. Metab. https://doi.org/10.1210/jc .2013-1274.

Chapuy, M. C., A. M. Schott, P. Garnero, D. Hans, P. D. Delmas, and P. J. Meunier. 1996. Healthy elderly French women living at home have secondary hyperparathyroidism and high bone turnover in winter. EPIDOS Study Group. J. Clin. Endocrinol. Metab. 81:1129-1133. https://doi.org/10.1210/jcem.81.3.8772587.

Chen, M., A. Pan, V. S. Malik, and F. B. Hu. 2012. Effects of dairy intake on body weight and fat: a meta-analysis of randomized controlled trials. Am. J. Clin. Nutr. 96:735-747. https://doi.org/ 10.3945/ajcn.112.037119.

Cho, H.-J., H.-C. Kang, S.-A. Choi, Y.-C. Ju, H.-S. Lee, and H.-J. Park. 2005. The possible role of $\mathrm{Ca}^{2+}$ on the activation of microsomal triglyceride transfer protein in rat hepatocytes. Biol. Pharm. Bull. 28:1418-1423

Dawson-Hughes, B., A. Mithal, J.-P. Bonjour, S. Boonen, P. Burckhardt, G. E.-H. Fuleihan, R. G. Josse, P. Lips, J. Morales-Torres, and N. Yoshimura. 2010. IOF position statement: Vitamin D rec- 
ommendations for older adults. Osteoporos. Int. 21:1151-1154. https://doi.org/10.1007/s00198-010-1285-3.

DiRienzo, D. B. 2014. Effect of probiotics on biomarkers of cardiovascular disease: Implications for heart-healthy diets. Nutr. Rev. 72:18-29. https://doi.org/10.1111/nure.12084.

El-Abbadi, N. H., M. C. Dao, and S. N. Meydani. 2014. Yogurt: Role in healthy and active aging. Am. J. Clin. Nutr. 99:1263S-1270S. https://doi.org/10.3945/ajcn.113.073957.

Elamin, M. B., N. O. Abu Elnour, K. B. Elamin, M. M. Fatourechi, A. A. Alkatib, J. P. Almandoz, H. Liu, M. A. Lane, R. J. Mullan, A. Hazem, P. J. Erwin, D. D. Hensrud, M. H. Murad, and V. M. Montori. 2011. Vitamin D and cardiovascular outcomes: A systematic review and meta-analysis. J. Clin. Endocrinol. Metab. 96:1931-1942. https://doi.org/10.1210/jc.2011-0398.

Gao, D., N. Ning, C. Wang, Y. Wang, Q. Li, Z. Meng, Y. Liu, and Q. Li. 2013. Dairy products consumption and risk of type 2 diabetes: Systematic review and dose-response meta-analysis. PLoS One 8:e73965. https://doi.org/10.1371/journal.pone.0073965.

George, P. S., E. R. Pearson, and M. D. Witham. 2012. Effect of vitamin D supplementation on glycaemic control and insulin resistance: A systematic review and meta-analysis. Diabet. Med. 29:e142-e150. https://doi.org/10.1111/j.1464-5491.2012.03672.x.

Ghouri, Y. A., D. M. Richards, E. F. Rahimi, J. T. Krill, K. A. Jelinek, and A. W. DuPont. 2014. Systematic review of randomized controlled trials of probiotics, prebiotics, and synbiotics in inflammatory bowel disease. Clin. Exp. Gastroenterol. 7:473-487. https:// doi.org/10.2147/CEG.S27530.

Goldenberg, J. Z., C. Yap, L. Lytvyn, C. K.-F. Lo, J. Beardsley, D. Mertz, and B. C. Johnston. 2017. Probiotics for the prevention of Clostridium difficile-associated diarrhea in adults and children. Cochrane Database Syst. Rev. 12:CD006095. https://doi.org/10 1002/14651858.CD006095.pub4.

Griffith, L. E., G. H. Guyatt, R. J. Cook, H. C. Bucher, and D. J. Cook. 1999. The influence of dietary and nondietary calcium supplementation on blood pressure: An updated meta-analysis of randomized controlled trials. Am. J. Hypertens. 12:84-92.

Heaney, R. P. 2004. Functional indices of vitamin D status and ramifications of vitamin D deficiency. Am. J. Clin. Nutr. 80:1706S1709S. https://doi.org/10.1093/ajcn/80.6.1706S.

Higgins, J. P. T., D. G. Altman, P. C. Gøtzsche, P. Jüni, D. Moher, A. D. Oxman, J. Savovic, K. F. Schulz, L. Weeks, J. A. C. Sterne, Cochrane Bias Methods Group, and Cochrane Statistical Methods Group. 2011. The Cochrane Collaboration's tool for assessing risk of bias in randomised trials. BMJ 343:d5928.

Holick, M. F. 2007. Vitamin D deficiency. N. Engl. J. Med. 357:266281. https://doi.org/10.1056/NEJMra070553.

Holick, M. F., N. C. Binkley, H. A. Bischoff-Ferrari, C. M. Gordon, D A. Hanley, R. P. Heaney, M. H. Murad, and C. M. Weaver., and Endocrine Society. 2011. Evaluation, treatment, and prevention of vitamin D deficiency: An Endocrine Society clinical practice guideline. J. Clin. Endocrinol. Metab. 96:1911-1930. https://doi .org/10.1210/jc.2011-0385.

Holick, M. F., E. S. Siris, N. Binkley, M. K. Beard, A. Khan, J. T. Katzer, R. A. Petruschke, E. Chen, and A. E. de Papp. 2005. Prevalence of vitamin D inadequacy among postmenopausal North American women receiving osteoporosis therapy. J. Clin. Endocrinol. Metab. 90:3215-3224. https://doi.org/10.1210/jc.2004-2364.

Jafari, T., G. Askari, M. Mirlohi, S. H. Javanmard, E. Faghihimani, and A. A. Fallah. 2016a. Stability of Vitamin D3 in fortified yoghurt and yoghurt drink (Doogh). Adv. Biomed. Res. 5:52. https:/ /doi.org/10.4103/2277-9175.178796.

Jafari, T., E. Faghihimani, A. Feizi, B. Iraj, S. H. Javanmard, A. Esmaillzadeh, A. A. Fallah, and G. Askari. 2016b. Effects of vitamin D-fortified low fat yogurt on glycemic status, anthropometric indexes, inflammation, and bone turnover in diabetic postmenopausal women: A randomised controlled clinical trial. Clin. Nutr. https://doi.org/10.1016/j.clnu.2015.02.014.

Khalesi, S., J. Sun, N. Buys, and R. Jayasinghe. 2014. Effect of probiotics on blood pressure: A systematic review and meta-analysis of randomized, controlled trials. Hypertension 64:897-903. https:// doi.org/10.1161/HYPERTENSIONAHA.114.03469.
Lacour, B., C. Basile, T. Drüeke, and J. L. Funck-Brentano. 1982 Parathyroid function and lipid metabolism in the rat. Miner. Electrolyte Metab. 7:157-165.

Li, Q., and B. Xing. 2016. Vitamin D3-supplemented yogurt drink improves insulin resistance and lipid profiles in women with gestational diabetes mellitus: A randomized double blinded clinical trial. Ann. Nutr. Metab. 68:285-290. https://doi.org/10.1159/ 000447433.

Lips, P., D. Hosking, K. Lippuner, J. M. Norquist, L. Wehren, G. Maalouf, S. Ragi-Eis, and J. Chandler. 2006. The prevalence of vitamin D inadequacy amongst women with osteoporosis: An international epidemiological investigation. J. Intern. Med. 260:245254. https://doi.org/10.1111/j.1365-2796.2006.01685.x.

Luna, R. A., and J. A. Foster. 2015. Gut brain axis: Diet microbiota interactions and implications for modulation of anxiety and depression. Curr. Opin. Biotechnol. 32:35-41. https://doi.org/10 .1016/j.copbio.2014.10.007.

Ly, N. P., A. Litonjua, D. R. Gold, and J. C. Celedón. 2011. Gut microbiota, probiotics, and vitamin D: Interrelated exposures influencing allergy, asthma, and obesity? J. Allergy Clin. Immunol. 127:1087-1094. https://doi.org/10.1016/j.jaci.2011.02.015.

Mirhosseini, N., J. Rainsbury, and S. M. Kimball. 2018. Vitamin D supplementation, serum $25(\mathrm{OH}) \mathrm{D}$ concentrations and cardiovascular disease risk factors: A systematic review and meta-analysis. Front. Cardiovasc. Med. 5:87. https://doi.org/10.3389/fcvm.2018 .00087 .

Mohammadi-Sartang, M., N. Bellissimo, J. O. Totosy de Zepetnek, N. R. Brett, S. M. Mazloomi, M. Fararouie, A. Bedeltavana, M. Famouri, and Z. Mazloom. 2018. The effect of daily fortified yogurt consumption on weight loss in adults with metabolic syndrome: A 10-week randomized controlled trial. Nutr. Metab. Cardiovasc. Dis. https://doi.org/10.1016/j.numecd.2018.03.001.

Moher, D., A. Liberati, J. Tetzlaff, and D. G. Altman., and PRISMA Group. 2009. Preferred Reporting Items for Systematic Reviews and Meta-Analyses: The PRISMA statement. PLoS Med. 6:e1000097. https://doi.org/10.1371/journal.pmed.1000097.

Mostafai, R., R. Mohammadi, S.M. Nachvak, M. Rezaei, Y. Pasdar, H. Abdollahzad, F. Rezvanmadani, S. Moradi, M. Morvaridzadeh, P. Niazi, and K. Adeli. 2018. Fortified yogurt with vitamin D as a cost-effective food to prevent diabetes: A randomized double-blind clinical trial. J. Funct. Foods 42:137-145.

Naylor, K., and R. Eastell. 2012. Bone turnover markers: Use in osteoporosis. Nat. Rev. Rheumatol. 8:379-389. https://doi.org/10 $.1038 /$ nrrheum.2012.86.

Nikooyeh, B., T. R. Neyestani, M. Farvid, H. Alavi-Majd, A. Houshiarrad, A. Kalayi, N. Shariatzadeh, A. Gharavi, S. Heravifard, N. Tayebinejad, S. Salekzamani, and M. Zahedirad. 2011. Daily consumption of vitamin D- or vitamin D + calcium-fortified yogurt drink improved glycemic control in patients with type 2 diabetes: A randomized clinical trial. Am. J. Clin. Nutr. https://doi.org/10 $.3945 /$ ajcn.110.007336.

Nikooyeh, B., T. R. Neyestani, N. Tayebinejad, H. Alavi-Majd, N. Shariatzadeh, A. Kalayi, M. Zahedirad, S. Heravifard, and S. Salekzamani. 2014. Daily intake of vitamin D- or calcium-vitamin Dfortified Persian yogurt drink (doogh) attenuates diabetes-induced oxidative stress: Evidence for antioxidative properties of vitamin D. J. Hum. Nutr. Diet. 27:276-283. https://doi.org/10.1111/jhn .12142 .

Ozen, M., G. Kocabas Sandal, and E. C. Dinleyici. 2015. Probiotics for the prevention of pediatric upper respiratory tract infections: A systematic review. Expert Opin. Biol. Ther. 15:9-20. https://doi .org/10.1517/14712598.2015.980233.

Paxman, J. R., J. C. Richardson, P. W. Dettmar, and B. M. Corfe. 2008. Daily ingestion of alginate reduces energy intake in freeliving subjects. Appetite 51:713-719. https://doi.org/10.1016/j .appet.2008.06.013.

Pereira-Santos, M., P. R. F. Costa, A. M. O. Assis, C. A. S. T. Santos, and D. B. Santos. 2015. Obesity and vitamin D deficiency: A systematic review and meta-analysis. Obes. Rev. 16:341-349. https:/ /doi.org/10.1111/obr.12239. 
Pilz, S., W. März, K. D. Cashman, M. E. Kiely, S. J. Whiting, M. F. Holick, W. B. Grant, P. Pludowski, M. Hiligsmann, C. Trummer, V. Schwetz, E. Lerchbaum, M. Pandis, A. Tomaschitz, M. R. Grübler, M. Gaksch, N. Verheyen, B. W. Hollis, L. Rejnmark, S. N. Karras, A. Hahn, H. A. Bischoff-Ferrari, J. Reichrath, R. Jorde, I. Elmadfa, R. Vieth, R. Scragg, M. S. Calvo, N. M. van Schoor, R. Bouillon, P. Lips, S. T. Itkonen, A. R. Martineau, C. LambergAllardt, and A. Zittermann. 2018. Rationale and plan for vitamin D food fortification: A review and guidance paper. Front. Endocrinol. (Lausanne) 9:373. https://doi.org/10.3389/fendo.2018.00373.

Ross, A. C., J. E. Manson, S. A. Abrams, J. F. Aloia, P. M. Brannon, S. K. Clinton, R. A. Durazo-Arvizu, J. C. Gallagher, R. L. Gallo, G. Jones, C. S. Kovacs, S. T. Mayne, C. J. Rosen, and S. A. Shapses. 2011. The 2011 report on dietary reference intakes for calcium and vitamin D from the Institute of Medicine: What clinicians need to know. J. Clin. Endocrinol. Metab. 96:53-58. https:/ /doi.org/10.1210/jc.2010-2704.

Savaiano, D. A. 2014. Lactose digestion from yogurt: Mechanism and relevance. Am. J. Clin. Nutr. 99:1251S-1255S. https://doi.org/10 .3945 /ajcn.113.073023.

Shab-Bidar, S., T. R. Neyestani, and A. Djazayery. 2015a. Vitamin D receptor $\mathrm{Cdx}$-2-dependent response of central obesity to vitamin D intake in the subjects with type 2 diabetes: A randomised clinical trial. Br. J. Nutr. https://doi.org/10.1017/S0007114515003049.

Shab-Bidar, S., T. R. Neyestani, and A. Djazayery. 2015b. The interactive effect of improvement of vitamin D status and VDR FokI variants on oxidative stress in type 2 diabetic subjects: A randomized controlled trial. Eur. J. Clin. Nutr. 69:216-222. https://doi .org/10.1038/ejcn.2014.240.

Shab-Bidar, S., T. R. Neyestani, A. Djazayery, M. R. Eshraghian, A. Houshiarrad, A. Gharavi, A. Kalayi, N. Shariatzadeh, M. Zahedirad, N. Khalaji, and H. Haidari. 2011. Regular consumption of vitamin D-fortified yogurt drink (Doogh) improved endothelial biomarkers in subjects with type 2 diabetes: A randomized doubleblind clinical trial. BMC Med. https://doi.org/10.1186/1741-7015 $-9-125$.

SINU (Società Italiana di Nutrizione Umana). 2014. LARN tables 2014. Accessed Feb. 5, 2019. http://www.sinu.it/html/pag/tabelle _larn_2014_rev.asp.

Song, Y., L. Wang, A. G. Pittas, L. C. Del Gobbo, C. Zhang, J. E. Manson, and F. B. Hu. 2013. Blood 25-hydroxy vitamin D levels and incident type 2 diabetes: A meta-analysis of prospective studies. Diabetes Care 36:1422-1428. https://doi.org/10.2337/dc12 -0962 .

Teegarden, D., K. M. White, R. M. Lyle, M. B. Zemel, M. D. Van Loan, V. Matkovic, B. A. Craig, and D. A. Schoeller. 2008. Calcium and dairy product modulation of lipid utilization and energy expenditure. Obesity (Silver Spring) 16:1566-1572. https://doi .org/10.1038/oby.2008.232.

USDA. 2014. USDA Nutrient Database for Standard Reference. Release 27. Accessed Jul. 31, 2019. http://www.ars.usda.gov/ nutrientdata.

Vimaleswaran, K. S., D. J. Berry, C. Lu, E. Tikkanen, S. Pilz, L. T. Hiraki, J. D. Cooper, Z. Dastani, R. Li, D. K. Houston, A. R. Wood, K. Michaëlsson, L. Vandenput, L. Zgaga, L. M. Yerges-Armstrong, M. I. McCarthy, J. Dupuis, M. Kaakinen, M. E. Kleber, K. Jameson, N. Arden, O. Raitakari, J. Viikari, K. K. Lohman, L. Ferrucci, H. Melhus, E. Ingelsson, L. Byberg, L. Lind, M. Lorentzon, V. Salomaa, H. Campbell, M. Dunlop, B. D. Mitchell, K.-H. Herzig, A. Pouta, and A.-L. Hartikainen., Genetic Investigation of Anthro- pometric Traits-GIANT ConsortiumStreeten, E. A., E. Theodoratou, A. Jula, N. J. Wareham, C. Ohlsson, T. M. Frayling, S. B. Kritchevsky, T. D. Spector, J. B. Richards, T. Lehtimäki, W. H. Ouwehand, P. Kraft, C. Cooper, W. März, C. Power, R. J. F. Loos, T.J. Wang, M.-R. Järvelin, J. C. Whittaker, A. D. Hingorani, and E. Hyppönen. 2013. Causal relationship between obesity and vitamin D status: Bi-directional Mendelian randomization analysis of multiple cohorts. PLoS Med. 10:e1001383. https://doi.org/10 .1371/journal.pmed.1001383.

Wang, H., K. A. Livingston, C. S. Fox, J. B. Meigs, and P. F. Jacques. 2013. Yogurt consumption is associated with better diet quality and metabolic profile in American men and women. Nutr. Res. 33:18-26. https://doi.org/10.1016/j.nutres.2012.11.009.

Wang, H., L. M. Troy, G. T. Rogers, C. S. Fox, N. M. McKeown, J. B. Meigs, and P. F. Jacques. 2014. Longitudinal association between dairy consumption and changes of body weight and waist circumference: The Framingham Heart Study. Int. J. Obes. (Lond.) 38:299-305. https://doi.org/10.1038/ijo.2013.78.

Wang, L., Y. Song, J. E. Manson, S. Pilz, W. Marz, K. Michaelsson, A. Lundqvist, S. K. Jassal, E. Barrett-Connor, C. Zhang, C. B. Eaton, H. T. May, J. L. Anderson, and H. D. Sesso. 2012. Circulating 25-hydroxy-vitamin $\mathrm{D}$ and risk of cardiovascular disease: A meta-analysis of prospective studies. Circ. Cardiovasc. Qual. Outcomes 5:819-829. https://doi.org/10.1161/CIRCOUTCOMES .112 .967604 .

Weyland, P. G., W. B. Grant, and J. Howie-Esquivel. 2014. Does sufficient evidence exist to support a causal association between vitamin D status and cardiovascular disease risk? An assessment using Hill's criteria for causality. Nutrients 6:3403-3430. https:// doi.org/10.3390/nu6093403.

WHO. (World Health Organization). 2003. Prevention and management of osteoporosis. Geneva WHO technical report series no. 921. Accessed Jul. 31, 2019. https://apps.who.int/iris/handle/10665/ 42841.

WHO/FAO (World Health Organization and Food and Agriculture Organization). 2011. Pages 56-58 in Codex Standard for Fermented Milks; CODEX STAN-243-2003. Accessed Jul. 10, 2019. www .fao.org/input/download/standards/400/CXS_243e.pdf.

Witham, M. D., M. A. Nadir, and A. D. Struthers. 2009. Effect of vitamin D on blood pressure: A systematic review and meta-analysis. J. Hypertens. 27:1948-1954. https://doi.org/10.1097/HJH $.0 \mathrm{~b} 013 \mathrm{e} 32832 \mathrm{f075b}$.

Yu, S., D. Bruce, M. Froicu, V. Weaver, and M. T. Cantorna. 2008. Failure of $\mathrm{T}$ cell homing, reduced CD4/CD8alphaalpha intraepithelial lymphocytes, and inflammation in the gut of vitamin D receptor KO mice. Proc. Natl. Acad. Sci. USA 105:20834-20839. https://doi.org/10.1073/pnas.0808700106.

Zemel, M. B. 2004. Role of calcium and dairy products in energy partitioning and weight management. Am. J. Clin. Nutr. 79:907S-912S. https://doi.org/10.1093/ajcn/79.5.907S.

Zhang, Q., Y. Wu, and X. Fei. 2015. Effect of probiotics on body weight and body-mass index: A systematic review and meta-analysis of randomized, controlled trials. Int. J. Food Sci. Nutr. 67:571-580. https://doi.org/10.1080/09637486.2016.1181156.

Zittermann, A., S. Frisch, H. K. Berthold, C. Götting, J. Kuhn, K. Kleesiek, P. Stehle, H. Koertke, and R. Koerfer. 2009. Vitamin D supplementation enhances the beneficial effects of weight loss on cardiovascular disease risk markers. Am. J. Clin. Nutr. 89:13211327. https://doi.org/10.3945/ajcn.2008.27004. 